\title{
La iniciativa ciudadana europea (art. 11.4 TUE)*
}

\author{
Juan María Bilbao Ubillos \\ Catedrático de Derecho Constitucional \\ Universidad de Valladolid
}

\begin{abstract}
Sumario: I. Antecedentes. - II. La configuración de la ICE en el Tratado de Lisboa.- III. La gestación del proyecto de Reglamento: la resolución del Parlamento Europeo y el Libro Verde. - IV. Reglamento del PE y del Consejo relativo a la iniciativa ciudadana. 1. Número mínimo de Estados miembros de cuyos ciudadanos debe provenir la iniciativa (art. 7.1). 2. Número mínimo de ciudadanos por Estado miembro (art. 7.2 y anexo I). 3. Edad mínima exigida (art. 3.2). 4. Requisitos para promover una iniciativa (art. 3.1). 5 Forma y redacción de la iniciativa ciudadana. 6. Registro de las iniciativas propuestas (art. 4). 7. Procedimientos y condiciones para la recogida y verificación de firmas (arts. 5, 6 y 8). 8. Plazo de recogida de firmas (art. 5.4). 9. La decisión sobre la admisibilidad de las iniciativas presentadas. 10. Examen de la iniciativa por la Comisión (arts. 9 y 10). 11. Requisitos exigibles a los organizadores: transparencia y financiación (art. 9). 12. Protección de datos de carácter personal (art. 12). 13. Entrada en vigor, modificación de los anexos y cláusula de revisión (arts. 16, 21 y 22).- - V. Una reflexión final sobre las expectativas que despierta la ICE.
\end{abstract}

Resumen: En este trabajo se analiza el proceso de gestación y aprobación de la Iniciativa Ciudadana Europea, la primera herramienta trasnacional de participación directa en el marco de la UE. Tras evocar los antecedentes de esta figura, se examina su configuración en el Tratado de Lisboa (art. 11.4 TUE), los trazos fundamentales de su fisonomía en la propuesta de Reglamento formulada por la Comisión en marzo de 2010 y los aspectos más relevantes de su regulación definitiva en el Reglamento 211/2011, de 16 de febrero de 2011, del Parlamento Europeo y del Consejo, que se aplicará a partir del 1 de abril de 2012: número mínimo de Estados miembros de cuyos ciudadanos debe provenir la iniciativa; número mínimo de ciudadanos por Estado miembro; requisitos para promover una iniciativa; forma y redacción de la iniciativa ciudadana; registro de las iniciativas propuestas; procedimientos, condiciones y plazos para la recogida y verificación de firmas; admisibilidad de las iniciativas presentadas; examen de la iniciativa por la Comisión; etc. El artículo se cierra con una reflexión final sobre las expectativas que despierta la ICE. No cabe duda de que apunta en la buena dirección, en la de reforzar la legitimidad

* Recibido el 18 de diciembre de 2011, aceptado el 18 de enero de 2012. 
democrática de la UE, pero no estamos en rigor ante una institución de democracia directa, porque no se transfiere a los ciudadanos la capacidad de decisión en un determinado ámbito. Mediante estas iniciativas se insta a la Comisión a que presente un proyecto legislativo sobre un asunto concreto, pero no es una propuesta vinculante. La Comisión no está obligada a hacerlo.

Palabras clave: Unión Europea, legitimidad democrática de las instituciones europeas, ciudadanía europea, participación directa, iniciativa legislativa popular.

Abstract: The process of drawing up and adoption of the regulation of the European Citizens' Initiative (ECI), as the first transnational tool for their direct political participation in the frame of the European Union, is the issue analyzed in this article. After evoking the background of the institution, and the way it is established in the Lisbon Treaty, the author considers the fundamental aspects of the ECI as it is drawn up in the proposal of the Commission, of march 2010, and in the definitive Regulation 211/2011, of 16 February 2011, of the European Parliament and the Council, that will become effective in April 2012. Thus, and in particular, aspects as the following are examined: minimum number of Member States' signatories citizens required, minimum number of signatories citizens per Member State required, requirements about the Initiative proposal, registration and certification of the initiatives, the procedure of signatures verification, the procedure for the examination of a citizens' initiative by the Commission... The final part of the commentary includes a global consideration about the new institution, in which the author appreciates the advance of reinforcing the democratic legitimacy of the Union even though the Initiative is not truly a direct participation institution so far it does not empower citizens to decide by themselves about any specific issue: the initiatives can urge the Commission to bring in a legislative proposal but are not legally binding.

Keywords: European Union, democratic legitimacy of the European institutions, European citizenship, direct participation, citizen's legislative initiative.

\section{Antecedentes}

La idea de una ICE, como derecho de participación política reconocido a los ciudadanos europeos, no es nueva. Se insiste mucho en su carácter innovador, pero es una novedad sólo relativa. En los últimos veinte años se han lanzado diversas propuestas en esa dirección. El primer paso realmente decisivo para la ICE se da en junio de 2003, cuando la Convención sobre el Futuro de Europa decide, en el último momento y de manera sorpresiva, incluirla en el texto del Tratado constitucional, gracias al empeño de unas cuantas organizaciones no gubernamentales, y de dos miembros de la Con- 
vención: el eurodiputado del PPE Alain Lamassoure y el parlamentario socialdemócrata alemán Jürgen Meyer ${ }^{1}$.

El artículo I-47 (4) del Tratado que establece una Constitución para Europa, aprobado por el Consejo europeo el 18 de junio de 2004 y firmado solemnemente en Roma el 29 de octubre de ese mismo año ${ }^{2}$ prevé por primera vez esta herramienta trasnacional de democracia directa. Y lo hace en los siguientes términos: «Un grupo de al menos un millón de ciudadanos de la Unión, que sean nacionales de un número significativo de Estados miembros, podrá tomar la iniciativa de invitar a la Comisión, en el marco de sus atribuciones, a que presente una propuesta adecuada sobre cuestiones que estos ciudadanos estimen que requiere un acto jurídico de la Unión para los fines de la aplicación de la Constitución. La ley europea establecerá las disposiciones relativas a los procedimientos y condiciones necesarios para la presentación de esta iniciativa ciudadana, incluido el número mínimo de Estados miembros de los que deben proceder los ciudadanos que la presenten».

Como es sabido, el proyecto de nuevo Tratado fue rechazado por Francia (mayo de 2005) y Holanda (junio de 2005) en sendos referéndum nacionales y al no ser ratificado por los 27 Estados miembros no llegó a entrar en vigor.

\section{La configuración de la ICE en el Tratado de Lisboa}

El Tratado por el que se modifican el Tratado de la Unión Europea y el Tratado constitutivo de la Comunidad Europea, se firmó en Lisboa el 13

${ }^{1}$ Sólo una semana antes de que finalizase sus trabajos, una abrumadora mayoría del Presidium había rechazado su inclusión en el texto final. En ese momento crucial, lejos de rendirse, los activistas de diversas ONGs redoblaron sus esfuerzos para convencer a los miembros del Presidium. Durante esa decisiva semana el respaldo político de muchos miembros de la Convención jugó también un papel muy importante. Finalmente, la acción común de políticos y activistas logró cambiar la marcha de los acontecimientos: alguien describió esta secuencia como «montaña rusa». Era la primera vez que personas y grupos de diferentes países europeos presionaban de forma concertada en favor de una participación directa de los ciudadanos en el curso de una reforma de los Tratados y fue una sorpresa que ese esfuerzo tuviera éxito. Vid. M. AFLER, European Citizens' Initiative. Legal options for implementation below the constitutional level, Democracy International, 2006, pp. 4 y ss (www.democracyinternational.org); A. AUER, «European Citizens' Initiative», en European Constitutional Law Review, n. ${ }^{\circ}$ 1, 2005, pp. 79-86; V. CUESTA, «The Future of the European Citizen Initiative», en B. KAUFMANN/A. LAMASSOURE/J. MEYER (eds.), Transnational Democracy in the Making, Initiative \& Referendum Institute Europe, 2004, pp. 72 y ss; y S. HUG, Voices of Europe: citizens, referendums, and European integration, Rowman \& Littlefield Publishers, Oxford, 2003, pp. 7 y ss.

${ }^{2}$ C 310/34, Diario Oficial de la Unión Europea de 16.12.2004. 
de diciembre de $2007^{3}$ y entró en vigor el 1 de diciembre de 2009. Ya en su preámbulo se subraya el deseo de «completar el proceso iniciado por el Tratado de Ámsterdam y el Tratado de Niza con el fin de reforzar la eficacia y la legitimidad democrática de la Unión».

El Título II, que contiene las «disposiciones sobre los principios democráticos», formuladas en términos muy similares, cuando no idénticos, al Título VI del frustrado TCE («De la vida democrática de la Unión»), se abre con un artículo $9^{4}$, que tras señalar que «será ciudadano de la Unión toda persona que tenga la nacionalidad de un Estado miembro», una condición que se añade a la ciudadanía nacional sin sustituirla, sienta las bases que sustentan la arquitectura democrática de las instituciones comunes. De entrada, se afirma con meridiana claridad que «el funcionamiento de la Unión se basa en la democracia representativa» (art. 10.1), de modo que los ciudadanos europeos, además de estar representados en sus respectivos Parlamentos nacionales, «estarán directamente representados en la Unión a través del Parlamento Europeo» (art. 10.2) .

Pero este cauce no agota todas las posibilidades de participación. A renglón seguido se dice que todo ciudadano «tiene derecho a participar en la vida democrática de la Unión» y eso implica que «las decisiones serán tomadas de la forma más abierta y próxima posible a los ciudadanos» (art. 10.3), que «las instituciones mantendrán un diálogo abierto, transparente y regular con las asociaciones representativas y la sociedad civil» (art. 11.2) y que los ciudadanos tendrán la posibilidad de «expresar e intercambiar públicamente sus opiniones en todos los ámbitos de actuación de la Unión» (art. 11.1). Y esa participación activa se articulará, entre otros instrumentos, a través de los partidos políticos a escala europea, que «contri-

3 2007/C 306/01; Diario Oficial de la Unión Europea 17.12.2007.

${ }^{4}$ Art. 8 en la versión originaria. Pero aquí vamos a manejar la versión consolidada (2008/C 115/01; Diario Oficial de la Unión Europea de 9.5.2008)

5 No cabe duda de que la elección por sufragio universal directo del Parlamento Europeo desde el año 1979 ha aportado al proceso de integración europea un mayor grado de legitimidad democrática, vinculándolo directamente a la voluntad popular. Es más, desde la entrada en vigor del Tratado de Maastricht en 1993, todo ciudadano de la Unión, con independencia de su nacionalidad, tiene derecho a ejercer su derecho de sufragio activo y pasivo en las elecciones europeas y locales en el Estado miembro en que residan. De hecho, tras las elecciones de junio de 2009, en el Parlamento Europeo hay cinco eurodiputados que fueron elegidos en un Estado miembro distinto a aquel en el que nacieron. Pero no es menos cierto que las elecciones europeas se vienen registrando tasas de participación muy bajas. Entre las posibles causas de ese desinterés habría que consignar la ausencia de partidos políticos genuinamente europeos y de una opinión pública europea, que hace que sean elecciones con un perfil muy desdibujado (se ven como una oportunidad para castigar a los Gobiernos nacionales de turno y los debates se centran muchas veces en temas internos, como una segunda vuelta de las elecciones generales). 
buirán a formar la conciencia política europea y a expresar la voluntad de los ciudadanos de la Unión» (art. 10.4).

Este llamamiento a la participación activa y directa en la definición de las políticas comunitarias, formulado de manera genérica, no constituye una novedad. Sí representa, en cambio, un avance respecto a las previsiones contenidas en los Tratados anteriores (con la salvedad, ya señalada, del non nato TCE) la inclusión de la iniciativa ciudadana como procedimiento que permite canalizar esa voluntad de participación, de mayor protagonismo, cuya existencia se presupone. Esta nueva herramienta se describe en el artículo art. 11.4 de la siguiente forma: «Un grupo de al menos un millón de ciudadanos de la Unión, que sean nacionales de un número significativo de Estados miembros, podrá tomar la iniciativa de invitar a la Comisión Europea, en el marco de sus atribuciones, a que presente una propuesta adecuada sobre cuestiones que estos ciudadanos estimen que requieren un acto jurídico de la Unión en aplicación de los Tratados».

Como puede apreciarse, la única diferencia con la redacción del art. I-47 del TCE radica en el inciso final: mientras allí se decía «en aplicación de la Constitución», ahora se dice «en aplicación de los Tratados». Aunque no es seguro que esa fuese la voluntad de los redactores del precepto, lo cierto es que esta última referencia ha sido interpretada por la mayoría de la doctrina en el sentido de que este cauce no podrá servir de vehículo para proponer reformas del texto de los Tratados, del Derecho primario de la UE. Sólo podrán admitirse, por tanto, las propuestas de modificación de la legislación comunitaria compatibles con lo dispuesto en los Tratados ${ }^{6}$.

Esta facultad, que no se formula literalmente como un derecho subjetivo, a diferencia de otros derechos de participación política (como el derecho de sufragio o el de petición), se reserva a los ciudadanos europeos, sin que pueda extenderse a los nacionales de terceros países residentes en la Unión ${ }^{7}$. En cuanto a su ámbito objetivo, se delimita en positivo: se circunscribe a aquellas materias respecto de las cuales la Comisión tiene atribuida iniciativa o competencia legislativa. No encontramos un listado de materias excluidas, como en España.

${ }^{6}$ Esta exclusión, cuyo alcance podría precisar en su caso el TJUE, es importante, porque impide la presentación de iniciativas que comporten la modificación de los vigentes Tratados, que, a diferencia de las Constituciones nacionales, contienen una regulación muy detallada, que en los Estados miembros formaría parte de la normativa legal o reglamentaria (Derecho secundario). Para algunos, excluir esta posibilidad de enmendar los Tratados impediría a los ciudadanos europeos jugar un papel activo en los asuntos políticos más importantes.

7 Una limitación que Víctor Cuesta califica de «particularmente reprochable» (Participación directa e iniciativa legislativa del ciudadano en democracia constitucional, Thomson/ Civitas, 2008, pp. 413 y 418). 
El art. 11.4 añade que los procedimientos y las condiciones preceptivas para la presentación de una iniciativa de este tipo se fijarán en un Reglamento adoptado por el Parlamento Europeo y el Consejo, con arreglo al procedimiento legislativo ordinario. En el Tratado ya se definen las características básicas de las iniciativas ciudadanas: deben estar respaldadas con la firma de al menos un millón de ciudadanos, el 0,2\% de la población total de la Unión, que es un porcentaje asequible si se compara con las 500.000 firmas que exige nuestra Constitución (un 0,9 aproximadamente) o las exigidas en otros países que prevén este instrumento de participación ${ }^{8}$, siempre que esos ciudadanos sean nacionales de un número significativo de países de la $\mathrm{UE}^{9}$, y tienen que referirse a un ámbito en el que la Comisión tenga competencias.

Pero son muchas las cuestiones que quedan en el aire, los detalles que el Reglamento terminará de concretar o perfilar para poder ejercer este derecho: el número mínimo de países de los que debe proceder la iniciativa; cuántos ciudadanos deben firmarla como mínimo en cada país; la definición exacta del término ciudadano en este contexto, la edad mínima de los firmantes; la estructura y la forma que han de adoptar las iniciativas; y numerosas cuestiones de procedimiento: normas sobre la recogida, comprobación y autentificación de las firmas, plazos para la recogida de firmas; normas sobre el registro oficial de las iniciativas; normas de transparencia y financiación (aplicables a los promotores); posible plazo máximo de respuesta por parte de la Comisión; cómo actuar cuando coincidan varias iniciativas sobre un mismo asunto, etc.

La ICE no es, por cierto, la única puerta que se abre a la participación directa en el seno de la Unión. En el mismo artículo 24 del Tratado de Funcionamiento de la UE se reconocen otros tres derechos de todo ciudadano de la Unión: el derecho de petición ante el Parlamento Europeo, de conformidad con lo dispuesto en el artículo 22710; el derecho a dirigirse al Defen-

${ }^{8}$ Sólo la Constitución italiana prevé un porcentaje menor: 50.000 electores, según el art. $71 \mathrm{CI}$.

${ }^{9}$ El reto es precisamente reunir a un número significativo de ciudadanos de diferentes países en torno a una causa común.

${ }^{10}$ En efecto, los ciudadanos europeos cuentan ya con la posibilidad de formular peticiones al Parlamento Europeo, un derecho que tienen reconocido desde el Tratado de Maastricht. En virtud de lo dispuesto en el artículo 227 del TFUE, cualquier ciudadano de la Unión, así como cualquier persona física o jurídica que resida o tenga su domicilio social en un Estado miembro, puede presentar, individualmente o asociado con otras personas, una petición sobre un asunto que sea responsabilidad de la Unión (dentro de su ámbito de actuación) y que le afecte directamente. La petición, que debe redactarse en una de las lenguas oficiales de la UE y presentarse por correo postal o por vía electrónica, puede consistir en una solicitud, una queja u observación relativa a la aplicación del Derecho comunitario, o un llamamiento dirigido al Parlamento Europeo para que tome posición ante un asunto concreto. La identidad de los autores de las peticiones y el número asignado a cada petición se inscriben en el registro general por orden de 
sor del Pueblo, con arreglo a lo dispuesto en el artículo 228; y el derecho a dirigirse por escrito a cualquiera de las instituciones, órganos u organismos de la UE (Consejo, Parlamento Europeo, Comisión, Tribunal de Justicia, Banco Central Europeo, Tribunal de Cuentas, Comité Económico y Social, Comité de las Regiones y Defensor del Pueblo).

Con el reconocimiento a los europeos no sólo de libertades civiles o derechos en tanto que consumidores, sino también de derechos de participación política, se trata de reforzar su sentimiento de ciudadanía, de pertenencia a la Unión Europea, y su responsabilidad como actores protagonistas del proceso político. A la participación electoral se suman las múltiples vías abiertas para hacer posible una participación más directa en la formulación de las políticas comunitarias, de forma individual o a través de asociaciones y organizaciones no gubernamentales.

No se trata, obviamente, de un cambio de modelo, no se propone un sistema alternativo. Tanto a escala nacional, en cada uno de los Estados miembros de la UE, como a escala europea, rige un modelo de democracia representativa en el que los ciudadanos eligen a quienes van a tomar las decisiones en su nombre. Se trata de introducir mecanismos de participación directa que sirvan de complemento del sistema representativo, que contribuyan al objetivo de refrescar el circuito democrático, de oxigenar el sistema

recepción y se anuncian en los Plenos del Parlamento. Los anuncios figuran en el acta de la sesión, que se publica en el Diario Oficial de la UE. Una Comisión de Peticiones, integrada por 34 miembros, se encarga de tramitar esas peticiones e informar al peticionario de las decisiones que adopte. Las reuniones de esta Comisión son públicas y los peticionarios que lo soliciten pueden asistir a las reuniones en que se examinen sus peticiones. Si la petición cumple los requisitos establecidos, será admitida a trámite y seguirá el curso que decida la Comisión. Según los casos, podrá acordar alguna de las medidas siguientes: pedir a la Comisión Europea que efectúe una investigación preliminar e informe de si se respeta o se infringe la legislación comunitaria pertinente, trasmitir la petición a otras comisiones del Parlamento Europeo para que éstas informen o inicien otras acciones en el marco de sus competencias, adoptar las medidas que considere adecuadas para tratar de resolver un problema o dar una respuesta adecuada al peticionario; $y$, en casos excepcionales, preparar y presentar un informe completo al Parlamento para que sea votado en sesión plenaria o bien efectuar una visita al país o a la región de que se trate para recoger información sobre el terreno y presentar un informe de comisión con sus observaciones y recomendaciones. En todo caso, los actos de la Comisión de Peticiones no podrán invalidar las decisiones adoptadas por las autoridades competentes de los Estados miembros (el Parlamento Europeo no puede revocar, por ejemplo, decisiones de los tribunales nacionales). Lo que interesa resaltar es que la petición se dirige al Parlamento, mientras que la ICE, que es necesariamente una propuesta compartida por ciudadanos de diferentes países, se dirige a la Comisión. Y ese es precisamente el factor que marca la diferencia entre la ICE y las iniciativas legislativas populares previstas en los ordenamientos nacionales, porque estas últimas se presentan directamente en los respectivos Parlamentos y son objeto de debate y aprobación (en su caso) si cumplen los requisitos establecidos para su admisión a trámite. En el caso de la ICE, no hay garantías de que la propuesta acceda al PE para ser discutida por los eurodiputados, porque la Comisión puede decidir no presentar el correspondiente proyecto legislativo. 
político y frenar el alarmante alejamiento de los ciudadanos. No son ingredientes incompatibles, contrapuestos. Es una cuestión de dosis, de encontrar la dosis apropiada. Los ciudadanos recuperarían su propia voz en determinadas circunstancias. De las dos herramientas de participación directa que pueden emplearse con ese fin, el referéndum y la iniciativa legislativa ciudadana, la primera no está disponible, no se contempla en la escena europea, ni para ratificar las leyes ni para ratificar las reformas introducidas en los Tratados constitutivos. No se ha previsto tampoco la celebración de consultas de iniciativa popular.

\section{La gestación del proyecto de Reglamento: la resolución del Parlamento Europeo y el Libro Verde}

En el proceso de preparación del Reglamento al que el Tratado remite la regulación de los procedimientos y condiciones preceptivas para la presentación de una iniciativa ciudadana, hay que mencionar, en primer lugar, la Resolución del Parlamento Europeo, de 7 de mayo de 2009, por la que se solicita a la Comisión que presente sin demora una propuesta de Reglamento. Esta Resolución incluye un anexo con Recomendaciones sobre el contenido de la citada propuesta.

Por su parte, la Comisión Europea elaboró un Libro verde en noviembre de $2009^{11}$ y puso en marcha una consulta pública sobre la Iniciativa Ciudadana con la finalidad de recabar los puntos de vista de todas las partes interesadas sobre un conjunto de cuestiones a regular en el futuro Reglamento. La consulta pública, abierta durante dos meses y medio, hasta el 31 de enero de 2010, brindó a los particulares interesados, asociaciones, empresarios y autoridades públicas la oportunidad de expresar su opinión sobre cómo debe funcionar en la práctica la iniciativa de los ciudadanos ${ }^{12}$. Las respuestas a

11 El Libro Verde sobre una Iniciativa Ciudadana Europea, fechado el 11 de noviembre de 2009 y disponible en las 23 lenguas oficiales de la Unión, proporciona información de referencia y plantea una serie de cuestiones de orden práctico que han de precisarse y aclararse para poder implementar estas iniciativas.

${ }^{12}$ La Comisión Europea, se lee en la introducción, «acoge con agrado la introducción de la iniciativa ciudadana, que permitirá oír mejor la voz de los ciudadanos europeos al concederles el derecho de solicitar directamente a la Comisión que presente nuevas iniciativas políticas. Dará una nueva dimensión a la democracia europea, complementará el conjunto de derechos relacionados con la ciudadanía de la Unión e intensificará el debate público en torno a las políticas europeas, ayudando a construir un auténtico espacio público europeo. Su aplicación reforzará la participación de los ciudadanos y la sociedad civil organizada en la configuración de las políticas de la UE». Al anunciar la consulta, la Comisaria Margot Wallström afirmó que el nuevo instrumento democrático debía ser «accesible, transparente y cómodo». 
las diez cuestiones planteadas, remitidas por correo postal o electrónico y agrupadas en tres secciones (ciudadanos, organizaciones - inscritas o no en el Registro de Grupos de Interés ${ }^{13}$ - y autoridades públicas ${ }^{14}$ ) se publicaron en el sitio habilitado por la Comisión, que se comprometió a estudiar y tener en cuenta las aportaciones recibidas a la hora de elaborar el proyecto de reglamento ${ }^{15}$ ). La convocatoria despertó un interés perfectamente descriptible. Dentro del plazo establecido se recibieron 329 respuestas. De ellas, 160 de ciudadanos individuales interesados, 133 de organizaciones y 36 de autoridades públicas (con escasa presencia española, por cierto, en los dos últimos apartados $)^{16}$. El desarrollo de la iniciativa ciudadana europea sobre la base del artículo 11.4 del TUE fue objeto asimismo de un vivo debate el 24 de marzo en el Pleno del Parlamento Europeo ${ }^{17}$.

${ }^{13}$ Entre los grupos registrados que participaron en la consulta pública están, por ejemplo, la Confederación Europea de Sindicatos (CES), el Comité Citoyen pour une Europe Solidaire, el Movimento Federalista Europeo (sección italiana); Wir Sind Europa, organización austriaca fundada para reforzar la identidad europea; y Sentit Comú per Catalunya (SCxCAT), una asociación cívica de ámbito catalán, constituida en 2007.

14 Entre los organismos o entidades públicas que respondieron al cuestionario, cabe mencionar la Conferencia de Presidentes de Parlamentos de las Comunidades Autónomas (COPREPA), la Cámara de Diputados del Gran Ducado de Luxemburgo y la Asamblea Legislativa de la Región de Emilia-Romagna.

15 De hecho, invitó a todos los que habían contestado al cuestionario a una audiencia pública (public hearing), que tuvo lugar el 22 de febrero en Bruselas.

${ }^{16}$ Los participantes podían adherirse a las propuestas iniciales de la Comisión o sugerir alternativas y lo cierto es que aportaron algunas ideas interesantes y originales. Una de las que se repite con más insistencia es la necesidad de que el procedimiento sea sencillo de modo que sea una herramienta accesible, de fácil uso, al alcance de todos los ciudadanos europeos. No deberían introducirse trabas innecesarias que puedan dificultar en exceso la presentación o la declaración de apoyo a una iniciativa. Hay coincidencia también en la necesidad de establecer requisitos y condiciones de ejercicio comunes que guarden proporción con la naturaleza de la ICE.

17 En el curso de ese debate, intervino, entre otros, el eurodiputado Íñigo Méndez de Vigo, del Grupo PPE, que llamó la atención sobre la necesidad de hacer pedagogía, de explicar cómo se puede utilizar esa iniciativa legislativa para no frustrar expectativas. Y puso un ejemplo: en Internet ya han empezado a recoger firmas para fijar mediante una iniciativa popular la sede del Parlamento Europeo. Pues bien, eso no es posible, porque ese cambio exige una reforma en los Tratados y no puede ser objeto de una iniciativa ciudadana. El alemán Gerald Häfner, en nombre del Grupo Verts/ALE, se congratuló de la oportunidad que supone la ICE para la creación y desarrollo gradual de un demos europeo, pero alertó sobre el riesgo de que una iniciativa firmada por un millón de ciudadanos acabase en la basura sin más, sin miramiento alguno. Varios diputados de diferentes grupos reiteraron su postura favorable a una reducción del umbral de 1/3 de los Estados (un mínimo de 6 o 7 Estados sería suficiente) y reclamaron un mayor protagonismo del $\mathrm{PE}$, mediante la previsión, por ejemplo, de un debate sobre cada una de las iniciativas presentadas, que podría dar lugar a una declaración o a la emisión de una opinión. Otros pusieron el acento en la exigencia de transparencia financiera, para evitar su captura o secuestro por los grupos de presión, en la aceptación de las firmas 
Cumpliendo escrupulosamente el plazo que ella misma se había marcado, la Comisión hizo pública su propuesta de Reglamento el 31 de marzo de $2010^{18}$. La propuesta de la Comisión, que despejaba muchas incógnitas y dibujaba claramente, en sus trazos fundamentales, la fisonomía de la futura ICE, fue presentada al Consejo el 6 de abril. La Presidencia encargó el examen de la propuesta al Grupo Antici, que presentó los resultados de la primera ronda de debates en la sesión del Consejo de Asuntos Generales celebrada en abril. Tras estudiar y sopesar las aportaciones de los ministros, el Grupo continuó analizando la propuesta y presentó un segundo informe en la reunión del Consejo de Asuntos Generales del 7 de junio, que aprobó una Orientacion general relativa a un Reglamento del Parlamento Europeo y del Consejo regulador de la iniciativa ciudadana.

Paralelamente, tanto el Consejo como el Parlamento Europeo decidieron consultar al Comité de las Regiones (CDR) y al Comité Económico y Social Europeo (CESE), que aprobaron sus respectivos Dictámenes sobre la Propuesta el 10 de junio y el 14 de julio de 2010. En esas mismas fechas se inició el debate en torno a la propuesta en el Parlamento Europeo, cuya Comisión de Asuntos Constitucionales estudió el 22 de junio un primer documento de trabajo sobre la misma, del que fueron ponentes la parlamentaria húngara Zita Gurmai y el francés Alain Lamassoure. También se examina en la Comisión de Peticiones y en las de Cultura y Educación, y Libertades civiles, Justicia y Asuntos interiores. Tras intensas negociaciones con representantes de la Comisión Europea y del Consejo, la Comisión de Asuntos Constitucionales aprobó finalmente su informe el 2 de diciembre ${ }^{19}$ y el Pleno del Parlamento Europeo fijó definitivamente su posición en su sesión del 15 de diciembre de $2010^{20}$.

electrónicas, o en la importancia de regular de forma adecuada el control de admisibilidad (con propuestas muy diferentes). Pero no todos los oradores fueron tan complacientes u optimistas a la hora de valorar esta nueva herramienta. El holandés F. Vanhecke (NI), por ejemplo, no ocultó su escepticismo: es un mero paliativo, una farsa que pretende sugerir un mínimo de participación ciudadana, sin que esa participación forme parte realmente de la toma de decisión. Lo que necesitamos en Europa, añadió, son referendos vinculantes (sobre la adhesión de Turquía, por ejemplo).

${ }^{18} \operatorname{COM}(2010) 119$ final; 2010/0074 (COD). La Propuesta va acompañada de un documento de trabajo de la propia Comisión fechado también el 31 de marzo sobre el resultado de la consulta pública (Outcome of the public consultation on the Green Paper on a European Citizens' Initiative).

19 Proyecto de Resolución legislativa sobre del PE sobre la propuesta de Reglamento del PE y del Consejo regulador de la iniciativa ciudadana (Procedimiento legislativo ordinario: primera lectura).

20 En su Resolución, aprobada por una amplísima mayoría (628 votos a favor, 15 en contra y 24 abstenciones), el PE introduce una enmienda para aclarar en el primer considerando de la propuesta que «ese procedimiento permite a los ciudadanos dirigirse directamente a la 


\section{Reglamento del PE y del Consejo relativo a la iniciativa ciudadana}

Veamos cuáles son las líneas maestras del Reglamento, que modifica en algunos aspectos el texto de la propuesta de la Comisión, tras un detenido examen de las enmiendas sugeridas por los órganos que se pronunciaron o dictaminaron sobre la misma, incluyendo el Parlamento Europeo.

\section{Número mínimo de Estados miembros de cuyos ciudadanos debe provenir la iniciativa (art. 7.1)}

Según el Libro Verde, para determinar el umbral adecuado, es necesario tomar en consideración varios aspectos. En primer lugar, la razón que subyace a la exigencia de que los signatarios procedan de «un número significativo de Estados miembros» es garantizar que la iniciativa sea suficientemente representativa de un interés de la Unión. No cabe duda de que un umbral elevado garantizaría esa representatividad, pero también haría el procedimiento más oneroso. Por el contrario, un umbral demasiado bajo haría la iniciativa más accesible, pero menos representativa.

Una opción podría ser exigir que el umbral se fijase en una mayoría de los Estados miembros. En la actualidad, con 27 Estados miembros, la mayoría se cifraría en 14 Estados. Sin embargo, el uso del término «número significativo» parece indicar que no se ha previsto una mayoría, que es, por otra parte, un umbral demasiado elevado. Otra opción, la menos exigente de las posibles, podría consistir en fijar el umbral en una cuarta parte de los Estados miembros (7 países en la actualidad). Este es el umbral propuesto por el Parlamento Europeo en su Resolución de 7 de mayo de 2009, por analogía con el artículo 76 del TFUE, que establece que los actos relacionados con la cooperación judicial en materia penal o la cooperación policial pueden adoptarse por iniciativa de la cuarta parte de los Estados miembros ${ }^{21}$. En el Libro Verde, la Comisión rechaza ese argumento: no considera que exista una analogía tan clara entre el precedente que se invoca y la iniciativa ciudadana, ya que aquél se refiere a un sector muy específico, que no guarda relación con

Comisión para instarla a presentar una propuesta de acto legislativo de la Unión a los efectos de aplicación de los Tratados similar al derecho conferido al Parlamento Europeo en virtud del artículo 225 del Tratado de Funcionamiento de la Unión Europea (TFUE) y al Consejo en virtud del artículo 241 del TFUE».

${ }^{21}$ Según el PE, «el artículo 76 del TFUE establece que, si una propuesta legislativa obtiene el respaldo de una cuarta parte de los Estados miembros, cabe suponer que se ha tenido debidamente en cuenta el interés común europeo», por lo que «este número mínimo puede considerarse incontrovertible». 
la iniciativa ciudadana. Por otra parte, estima que un umbral constituido por la cuarta parte de los Estados miembros sería demasiado bajo para garantizar que los intereses de la Unión queden adecuadamente reflejados.

Una tercera opción podría consistir en fijar el umbral en un tercio de los Estados miembros, que se alcanzaría en la actualidad con 9 Estados. Este umbral es justamente el utilizado en una serie de disposiciones del Tratado que tienen un carácter más general: las que regulan la «cooperación reforzada», que establecen que deben participar «al menos nueve Estados miembros», y las que fijan el número de Parlamentos nacionales necesarios para poner en marcha el procedimiento de subsidiariedad previsto en el artículo 7.2 del Protocolo sobre la aplicación de los principios de subsidiariedad y proporcionalidad, adjunto a los Tratados. La Comisión considera que con un umbral de un tercio se lograría un equilibrio entre la exigencia de garantizar una representatividad adecuada, una genuina representación de un interés de la Unión, por un lado, y la necesidad de facilitar el recurso al instrumento, por el otro 22 .

Tal y como se apuntaba en el Libro Verde, la propuesta inicial de la Comisión fijó ese número en un tercio. A estos efectos, se considera que un firmante proviene del Estado miembro que haya emitido el documento de identificación que figura en su declaración de apoyo (art. 7.3) ${ }^{23}$. La postura adoptada por la Comisión (y el Consejo) no convence, sin embargo, al CESE, que en su Dictamen recomienda reducir el umbral mínimo de Estados miembros a una cuarta parte ${ }^{24}$. En consonancia con la tesis defendida

${ }^{22}$ La Comisión se decanta claramente por esta solución desde el principio y prueba de ello es el modo en que se formula la primera de las preguntas del cuestionario que se somete a consulta pública: «¿Considera que un tercio del número total de Estados miembros puede constituir el «número significativo de Estados miembros» que exige el Tratado? En caso negativo, ¿qué umbral considera apropiado y por qué?. Hay, por supuesto, respuestas para todos los gustos. La que concitó más apoyo fue la propuesta de $1 / 3$, pero fueron muchas las organizaciones que se inclinaron por un umbral de $1 / 4$.

${ }^{23}$ En este último punto, el Consejo propone un criterio distinto: «los firmantes se consideraran procedentes del Estado miembro que sea responsable de la verificación de su declaración de apoyo» (enmienda al art. 7.4). Criterio que hace plenamente suyo el PE en el texto aprobado en diciembre de 2010 (art. 7.3), en contra de lo que propuso semanas antes en su proyecto de Resolución la Comisión de Asuntos Constitucionales (enmienda n. ${ }^{\circ}$ 46: los firmantes se considerarán procedentes del Estado miembro donde tengan su residencia permanente) y había recomendado con anterioridad el CESE. El artículo 7.3 del Reglamento zanja la cuestión al secundar la postura defendida por el Consejo y el PE.

${ }^{24}$ De este modo, se aplicaría el mismo principio previsto para la constitución de partidos de ámbito europeo. No puede ser que una iniciativa de los ciudadanos europeos deba afrontar obstáculos mayores que los que se plantean para el registro de un partido europeo. Del mismo criterio participa el CDR, que estima que el establecimiento de un umbral mínimo de un tercio de los Estados miembros es demasiado elevado, porque dificulta el ejercicio de un derecho de participación directa de los ciudadanos en la vida democrática de la Unión. 
en su Resolución de 2009, el Parlamento Europeo siguió sosteniendo en su posición de diciembre de 2010 que el umbral debía fijarse en una cuarta parte de los Estados miembros ${ }^{25}$. Y es el criterio que finalmente se impuso en el Reglamento ${ }^{26}$.

\section{Número mínimo de ciudadanos por Estado miembro (art. 7.2 y anexo I)}

Tanto el PE en su Resolución de 2009 como la Comisión en el Libro Verde tienen muy claro que no basta con exigir la participación de un número mínimo de Estados. Consideran necesario establecer un número mínimo de firmas de ciudadanos que apoyan la iniciativa en cada uno de los Estados miembros participantes, para garantizar así la dimensión europea de la iniciativa. Iría en contra del espíritu del Tratado que una iniciativa pudiese ser promovida por un numeroso grupo de ciudadanos de un Estado miembro y por un número puramente simbólico de ciudadanos de otros Estados miembros (incluso por uno sólo en la hipótesis más extrema).

Dadas las enormes diferencias existentes entre los Estados miembros en cuanto a población, que oscila entre los 410.000 habitantes de Malta y los 82 millones de Alemania, no parece una buena solución, según el Libro Verde, exigir el apoyo de un número fijo de ciudadanos en cada Estado miembro. Una opción más equitativa sería establecer un porcentaje mínimo de la población de cada Estado. Este umbral podría fijarse por analogía con la proporción de ciudadanos de la Unión exigida para presentar una iniciativa ciudadana. Sobre un total aproximado de 500 millones de ciudadanos, un millón representa el $0,2 \%$ de la población de la Unión. Y ese mismo porcentaje, el 0,2\% de la población de cada Estado miembro en el que se recojan las firmas podría ser un umbral razonable (equivaldría a unos 160.000 ciudadanos en Alemania, 94.000 en España, 20.000 en Bélgica y 800 en Malta). Fue también la opción preferida en un primer momento (2009) por el Parlamento Europeo ${ }^{27}$. Conviene tener en cuenta que el porcentaje de ciudadanos requerido para promover una iniciativa legislativa en la mayoría de los Estados miembros que cuentan con un instrumento de

25 En el informe de la Comisión de Asuntos Constitucionales aprobado el 2 de diciembre se proponía incluso rebajar ese umbral hasta una quinta parte de los Estados (enmienda n. ${ }^{\circ} 44$ al art. 7.1).

26 «Los firmantes de una iniciativa ciudadana habrán de proceder de, al menos, un cuarto de los Estados miembros» (art. 7.1).

27 Dado que el artículo 11.4 del TUE exige como mínimo la firma de un millón de ciudadanos de la Unión de un total de 500 millones aproximadamente, esa misma relación 1/500 de la población de cada Estado puede considerarse suficientemente representativa. 
este tipo es notablemente superior. En Austria o España, ese porcentaje se eleva al 1,2\% de la población; asciende al 1,5\% Lituania y llega al 10\% en Letonia.

En este punto, la consulta pública fue determinante. En general, las entidades que respondieron al cuestionario coincidieron en la necesidad de fijar un número mínimo de firmas en cada Estado, aunque hubo quien sostuvo que no debería introducirse este requisito porque no está expresamente previsto en el Tratado. La mayoría está de acuerdo en exigir un umbral del 0,2\% del total de la población de cada Estado, pero no son pocos los que se decantan por un porcentaje inferior (el $0,1 \%$ en particular) alegando que el objetivo debería ser no desalentar la presentación de una iniciativa. Otros propusieron un sistema de escala móvil, con diferentes modalidades. Es un sistema más flexible: si no se alcanzase ese umbral mínimo en todos y cada uno de los Estados, ese revés podría compensarse con la participación de un mayor $n .^{\circ}$ de Estados miembros. Finalmente, un número significativo de respuestas, procedentes sobre todo de los Estados miembros más grandes y más pequeños, propusieron un enfoque alternativo al de establecer un umbral común para el conjunto de los Estados, aduciendo que fijar un mismo porcentaje para todos los Estados no resulta equitativo, porque es mucho más fácil, por ejemplo, conseguir el apoyo de 1000 ciudadanos de Luxemburgo (el 0,2\% de su población) que el de 160.000 en Alemania, y en general, es más fácil alcanzar los umbrales exigidos en un país pequeño que en uno grande.

Tras sopesar las opiniones expresadas en el curso de la consulta y en particular el argumento de que un porcentaje idéntico para todos los Estados miembros no sería justo, la Comisión reconsideró el criterio mantenido inicialmente en el Libro Verde y en su Propuesta de Reglamento optó por un umbral para cada Estado miembro decrecientemente proporcional a su población, con un máximo y un mínimo. Para garantizar que esos umbrales se basan en criterios objetivos, la Comisión los calculó a partir de un múltiplo del número de diputados de cada Estado miembro en el PE en la fecha de registro de la iniciativa ${ }^{28}$. El múltiplo escogido es 750 , con el fin de atender, por un lado, las demandas formuladas por numerosos actores interesados en fijar un umbral inferior al $0,2 \%$ de la población y tener en cuenta, por otro, la inquietud expresada ante un umbral demasiado bajo para los pequeños Estados miembros. En efecto, al utilizar un factor multiplicador de 750, el umbral para más de la mitad de los Estados miembros será inferior

28 En la Propuesta inicial de la Comisión se tomaba como referencia la composición del Parlamento Europeo acordada en el marco de la Conferencia Intergubernamental de 2007. En el anexo que se incluye en la Resolución legislativa del PE de 2010 ya se opera con la composición actual, establecida en el Tratado de Lisboa. 
o netamente inferior al 0,2\% de la población, mientras que, para los Estados más pequeños será más elevado. Con este sistema, el porcentaje mínimo de firmantes (la proporción respecto de la población total) será más bajo para los grandes países y más elevado para los pequeños. En aras de la claridad, esos umbrales se fijan para cada uno de los Estados miembros en el anexo I del Reglamento: oscilan entre los 74.250 de Alemania y los 3.750 de Malta o los 4.500 de Chipre, Estonia y Luxemburgo, pasando por los 54.000 de Francia, Italia y Reino Unido o los 37.500 de España y Polonia ${ }^{29}$.

\section{Edad mínima exigida (art. 3.4)}

Parece razonable establecer una edad mínima para poder respaldar una iniciativa ciudadana. Así se hace en todos los Estados en los que existen iniciativas de este tipo. En el Libro Verde, la Comisión baraja dos opciones. La primera es exigir la misma edad que para votar en las elecciones europeas en el Estado miembro en que uno resida, una edad mínima que está fijada en los 18 años en todos los Estados miembros, con la excepción de Austria, que la rebajó a los 16 años. Esta es, por otra parte, la práctica habitual en los Estados miembros: pueden apoyar una iniciativa ciudadana aquellos ciudadanos que pueden votar. Otra opción es fijar la edad mínima en el propio Reglamento. Si se optase por fijarla en los 18 años, como en casi todos los Estados miembros, el problema sería que de ese modo se excluye a los mayores de 16 y menores de 18 que pueden votar en Austria ${ }^{30}$. Pero fijar la edad mínima en 16 años con carácter general complicaría mucho la gestión del censo de electores, que sería distinto al manejado en los procesos elec-

${ }^{29}$ El Reglamento dota a la Comisión de competencias para modificar este anexo mediante actos delegados, de modo que se refleje en él cualquier modificación relativa a la composición del PE (art. 7.3). En cualquier caso, si las declaraciones de apoyo recogidas en un Estado miembro no alcanzasen el umbral mínimo, tales declaraciones se añadirían, por supuesto, al número total de firmas, pero los Estados en cuestión no se contabilizarán para sumar la cuarta parte de los Estados miembros requerida.

30 Por esa razón, el PE recomendó en su Resolución de 2009 que se permitiera la participación de todo ciudadano de la Unión que tuviera derecho de voto en virtud de la legislación de su propio Estado miembro. El Parlamento, que parte de la premisa de que «toda restricción del derecho de participación democrática y toda desigualdad de trato basada en la edad deben respetar el principio de proporcionalidad», considera deseable «evitar las interpretaciones contradictorias que surgirían, por ejemplo, si la edad mínima para participar en las elecciones europeas en un determinado Estado miembro fuera inferior a la edad mínima requerida para participar en una iniciativa ciudadana». En otras palabras, se inclina por no establecer una edad mínima superior a la prevista en cada país para las elecciones al PE. No se plantea, en cambio, la hipótesis inversa (fijar una edad inferior para la iniciativa). 
torales (habría que elaborar ex profeso un nuevo censo, una carga administrativa excesiva, que recaería sobre los Estados miembros).

A la vista de los resultados de la consulta ${ }^{31}$, la Propuesta de la Comisión fijó la edad mínima para apoyar una ICE en la mayoría electoral para las elecciones europeas. Y ese es el umbral que establece el Reglamento. En consecuencia, están habilitados para apoyar una iniciativa con su firma aquellos ciudadanos de la Unión que pueden votar en las elecciones europeas.

\section{Requisitos para promover una iniciativa (art. 3.1)}

¿Quiénes pueden promover u organizar una de estas iniciativas? A tenor de lo dispuesto en el art. 3 de la Propuesta de la Comisión, cuando se trate de una persona física ha de ser un ciudadano de la Unión en edad de votar en las elecciones europeas. Si fuese una persona jurídica u organización, debe estar establecida en un Estado miembro. Las organizaciones desprovistas de personalidad jurídica en virtud del Derecho nacional aplicable designarán a los representantes que asumirán obligaciones y responsabilidades en su nombre. Es verdad que en muchos ordenamientos nacionales se exige que la iniciativa sea presentada por ciudadanos o por comités compuestos por un número determinado de ciudadanos. La Comisión considera que un requisito de este tipo puede resultar demasiado gravoso a escala de la UE y prefiere no imponer restricción alguna, de modo que los promotores puedan ser tanto ciudadanos particulares como organizaciones. Como sucede con las peticiones formuladas al Parlamento Europeo.

En este punto, la Comisión de Asuntos Constitucionales del PE se apartó del criterio de la Comisión y sostuvo que lo lógico es que los organizadores sean personas físicas para que sea realmente un instrumento de los ciudadanos, aunque las personas jurídicas podrían apoyar a los organizadores, siempre que se hiciesen públicos la naturaleza y el coste de ese apoyo.

${ }^{31}$ La inmensa mayoría de los participantes en la consulta pública respaldó la idea de fijar una edad mínima para poder apoyar una ICE. Muchos consideraban que debería vincularse a la edad requerida en cada país para votar en las elecciones al PE. Algunos, sin embargo, creían que esa edad debería ser la misma en todos los Estados. Dentro de este grupo, no faltaban quienes proponían que se fijase en los 16 años, para fomentar así la participación cívica de las generaciones más jóvenes y su interés por las cuestiones europeas. Argumentaban que una iniciativa ciudadana no es una elección, sino sólo una propuesta para influir en la agenda política europea y que podría ser un buen rodaje para que los más jóvenes aprendieran a ejercer la ciudadanía y a tomar parte en el debate político y en el proceso de adopción de decisiones. En esta línea se manifestaron, por ejemplo, la CES y el Comité Citoyen pour une Europe Solidaire. 
Para que el proceso sea lo más europeo posible desde el principio, los organizadores deberían constituirse en un «comité ciudadano» de un mínimo de 7 personas que provengan de al menos una cuarta parte de los Estados miembros. Se podrían estudiar otras opciones, como la posibilidad de exigir a los organizadores una fianza o el respaldo de cargos de elección directa a la iniciativa, aunque albergan dudas sobre esta última exigencia, porque añadiría una dosis inoportuna de democracia representativa.

En la versión aprobada por el Pleno del PE y recogida finalmente en el Reglamento, se parte de la premisa de que para llevar a cabo con éxito una iniciativa ciudadana se requiere una estructura organizativa mínima. Dicha estructura debería consistir en un comité ciudadano, integrado por, al menos, siete personas físicas (los organizadores) residentes en, al menos, siete Estados miembros diferentes (art. 3.2). Este comité será el responsable de la preparación y registro de la iniciativa.

\section{Forma y redacción de la iniciativa ciudadana}

El texto del Tratado no especifica qué forma debe adoptar la iniciativa ciudadana. Pero parece conveniente establecer algunos requisitos para garantizar, entre otras cosas, que se pueda discernir fácilmente el asunto objeto de la misma y sus objetivos. Una opción sería exigir que la iniciativa adoptase la forma de un proyecto de acto legislativo, de un texto articulado. De hecho, en algunos Estados miembros (Austria, Italia, Polonia y España) las iniciativas tienen que presentarse de esa forma. Pero en el Libro Verde la Comisión estima que este requisito es «innecesariamente restrictivo y oneroso». Y se decanta por exigir únicamente que en el texto se expongan de forma clara y detallada el contenido y los objetivos de la propuesta, para no inducir a error a los signatarios y facilitar la labor de la Comisión a la hora de ofrecer una respuesta precisa y de justificarla. Esta opción no excluiría, por supuesto, la posibilidad de que los promotores adjuntasen un proyecto de acto legislativo como texto de referencia.

Sometida esta cuestión a consulta pública, la mayoría coincide en que los promotores tienen que definir el objeto material y los objetivos de su propuesta de una forma clara, sin ambigüedades. Y para facilitar precisamente esa operación, son muchos los que invitan a la Comisión a diseñar un formulario o plantilla a cumplimentar por los promotores. En un número considerable de contribuciones se exige algo más: que los promotores proporcionen las bases legales de su propuesta o que acompañen un proyecto legislativo redactado como tal. Por otra parte, muchos creen que a los promotores se les tendría que ofrecer apoyo y orientación, e incluso consejo o asesoramiento legal, en la preparación 
de las iniciativas ${ }^{32}$. Y algunos sostienen, además, que las instituciones comunitarias (la Comisión, el PE, el Ombudsman u otras) deberían hacerse cargo de la traducción de la iniciativa a todas las lenguas oficiales de la $\mathrm{UE}^{33}$.

La Propuesta de Reglamento no abordó en un apartado específico esta cuestión, pero de la regulación en varias disposiciones del texto de la fase de registro y admisión de las iniciativas se deduce sin esfuerzo que la Comisión mantiene el criterio apuntado en el Libro Verde y no considera necesario imponer a los promotores la carga de aportar un proyecto articulado de acto legislativo. Un punto de vista que comparten tanto el Consejo como el PE, y encuentra reflejo en la redacción final del Reglamento ${ }^{34}$.

\section{Registro de las iniciativas propuestas (art. 4)}

La Comisión defendió desde el primer momento la necesidad de que la iniciativa se formalizase o registrase de alguna forma antes de que diese comienzo la recogida de firmas, como sucede, por lo demás, en la mayoría de los Estados miembros ${ }^{35}$. Los promotores podrían registrarla en un sitio

32 El CDR defiende la existencia de mecanismos de asistencia práctica y técnica para todos los interesados en la organización de iniciativas (creando, por ejemplo, una ventanilla de información).

${ }^{33}$ En su dictamen, el CESE considera que los servicios de la Comisión deberán traducir a todos los idiomas oficiales de la Unión el resumen de la propuesta (en total, conforme al anexo II, unos 800 caracteres) y que, una vez registrada, la Comisión debería comprometerse a traducir el texto completo de la iniciativa. En la misma línea, el CDR sugiere la inclusión de fórmulas de ayuda para traducir a todas las lenguas de la UE las partes esenciales de una iniciativa que haya sido declarada admisible, con el fin de que todos los ciudadanos de la Unión puedan llegar a conocerla.

${ }^{34}$ En la versión final del anexo II (Datos exigidos para registrar una propuesta de iniciativa ciudadana), levemente modificada por el PE, sólo se mencionan los siguientes datos: el titulo de la iniciativa propuesta, con un máximo de 100 caracteres; el objeto de la misma, con un máximo de 200 caracteres; la descripción de los objetivos de la propuesta, con un máximo de 500 caracteres; las disposiciones del Tratado consideradas pertinentes por los organizadores de la acción propuesta; el nombre, la dirección postal, la nacionalidad y la fecha de nacimiento de los 7 miembros del comité ciudadano; y todas las fuentes de financiación y apoyo a la iniciativa propuesta en el momento del registro. No obstante, los organizadores podrán proporcionar en un anexo datos más concretos sobre el objeto, objetivos y antecedentes de la iniciativa y podrán proponer, en su caso, un proyecto de texto legislativo.

35 Un modus operandi que encontrará expresa acogida en el Reglamento: «Para asegurar la coherencia y la transparencia en relación con las iniciativas ciudadanas propuestas, y para evitar que se recojan firmas de apoyo a una propuesta de iniciativa ciudadana que no cumpla las condiciones previstas en el presente Reglamento, debe ser obligatorio registrar tales iniciativas en una página web facilitada por la Comisión antes de la recogida de las necesarias declaraciones de apoyo de los ciudadanos» (Considerando n. $\left.{ }^{\circ} 10\right)$. La necesidad de registrar la iniciativa antes de iniciar la recogida de declaraciones de apoyo se reitera en el art. 4.1). 
web específico facilitado por la Comisión a tal fin, suministrando además de sus datos personales (nombre, fecha de nacimiento, nacionalidad, domicilio) toda la información pertinente sobre la iniciativa propuesta (asunto, objetivos, antecedentes, etc.), que se pondría a disposición del público. El sistema, totalmente transparente, ofrecería entonces a los organizadores la confirmación del registro, la fecha y un número de registro, que serviría para poner en marcha la campaña de recogida de firmas.

La cuestión es si con ocasión de ese trámite puede ejercer la Comisión algún tipo de control. A diferencia del $\mathrm{PE}^{36}$, la Comisión no considera oportuno un control de admisibilidad antes de que comience la recogida de firmas. A su juicio, este tipo de control podría inducir a error al dar a entender que la Comisión emite una opinión favorable sobre las iniciativas propuestas ellas, que las admite basándose en razones no estrictamente formales, y podría retrasar el inicio de la campaña de recogida de firmas. Además, no es posible considerar de manera aislada la admisibilidad y el fondo de las iniciativas, por lo que no sería apropiado efectuar este examen en una fase tan temprana como la del registro.

Frente a la tesis sostenida por el PE, que considera, con buen criterio, que «es muy oportuno tener la seguridad jurídica de que dicha iniciativa es admisible, antes de recabar las manifestaciones de apoyo necesarias», para evitar gastar tiempo y esfuerzos en la recogida de firmas en vano, la Comisión admite que puede haber ciertas reticencias con respecto a la puesta en marcha de una iniciativa si existe el riesgo de que ésta pudiera ser rechazada en última instancia por incurrir en alguna causa de inadmisibilidad. Pero advierte que los criterios de admisibilidad son suficientemente claros y conocidos y cabe esperar, en buena lógica, que antes de poner en marcha una iniciativa, los promotores hayan estudiado cuidadosamente, entre otros

${ }^{36}$ En su Resolución de mayo de 2009, el PE se mostraba partidario de un control de admisibilidad formal por parte de la Comisión en el momento del registro. En cuanto a los criterios de admisión, sólo podría darse curso a una iniciativa si reúne los requisitos siguientes: 1) que se invite a la Comisión a presentar una propuesta de acto legislativo de la Unión; 2) que la Unión tenga competencias legislativas, con arreglo a los Tratados, en el ámbito de que se trate y que el derecho de presentar una propuesta legislativa en esa materia corresponda a la Comisión, y 3) que el acto legislativo que se solicite no sea manifiestamente contrario a los principios generales del Derecho aplicados en la Unión. En todo caso, ese control sería de naturaleza estrictamente jurídica (como el que realiza la Mesa del Congreso en España) y las causas de inadmisión serían tasadas. En el plazo de dos meses a contar desde la fecha del registro, la Comisión deberá pronunciarse acerca de la admisibilidad de la iniciativa. La decisión se comunicará a los promotores y se dará a conocer al público en general mediante su publicación en el Diario Oficial de la UE. Se informará de inmediato sobre la decisión al PE, al Consejo y a los Estados miembros. Además, la Comisión publicará en su sitio web, accesible al público, una lista de todas las iniciativas ciudadanas debidamente registradas. 
extremos, si ésta encaja dentro de la esfera de atribuciones de la Comisión. Y si no fuese así, añado yo, peor para ellos. El argumento es muy endeble (es, a mi juicio, uno de los flancos más vulnerables de la Propuesta) ${ }^{37}$.

En su Propuesta, la Comisión prevé un sistema obligatorio de inscripción de las iniciativas en un registro on line. Se daba respuesta así al amplio apoyo que esta medida recibió en la fase de consulta. Los promotores deberán registrarlas antes de emprender la recogida de las declaraciones de apoyo necesarias. Y deberán proporcionar además las informaciones descritas en el anexo II, en una de las lenguas oficiales de la Unión. La Comisión asignará a la iniciativa un número de registro único y remitirá una confirmación a los promotores. Las propuestas que puedan ser consideradas razonablemente como inadmisibles por ser «incorrectas», «abusivas» o carentes de seriedad no serán registradas (art. 4.3) y la Comisión rechazará asimismo el registro de propuestas que sean «manifiestamente contrarias a los valores de la Unión» (art. 4.4). Pero, con la salvedad de ese primer filtro, el control de admisibilidad, como veremos inmediatamente, se va a ejercer en un momento posterior. Tras el correspondiente registro, la propuesta estará disponible para el público y seguirá su curso, con arreglo al procedimiento establecido. Obviamente, el registro no significa que la Comisión apruebe o avale la iniciativa. En la Propuesta de la Comisión no se aclara si los promotores podrán retirar su iniciativa una vez registrada ${ }^{38}$.

37 En la consulta pública este asunto fue también muy controvertido. Por un lado, se observa una tendencia, sobre todo entre las organizaciones y autoridades públicas, a considerar que la admisibilidad de una iniciativa debería verificarse antes de proceder a la recogida de firmas, preferiblemente en el momento del registro. Creen que así se evitaría un despilfarro o derroche de recursos y la frustración entre los ciudadanos que hubiesen firmado en un número suficiente y que verían finalmente inadmitida su iniciativa. Entre los que defienden esta opción, hay quienes lo hacen para impedir el lanzamiento de iniciativas que podrán ser contrarias a los valores de la Unión o de la Carta de Derechos Fundamentales. También preocupa que las autoridades tengan que hacer uso de recursos públicos para validar las firmas de apoyo a iniciativas que finalmente podrían no ser admisibles. Sin embargo, entre quienes apoyan un control previo de admisibilidad hay diferentes puntos de vista acerca de quién sería el encargado de dicho control: para algunos correspondería a la Comisión, para otros a una instancia u órgano independiente. Por otro lado, hay quienes alegan en contra de un examen global de admisibilidad ex ante que el debate suscitado en el conjunto de Europa por la iniciativa es más importante que el resultado inmediato. Piensan que no es apropiado que la Comisión tenga la capacidad para abortar desde el principio un debate público y una campaña de difusión en torno a una iniciativa, aunque no encaje dentro de sus competencias.

38 En el anexo de recomendaciones de su Resolución de 2009, el PE sí decía que «los organizadores de una iniciativa ciudadana podrán retirarla en todo momento. En tal caso, se considerará no registrada y será retirada de la lista mencionada de la Comisión» [(5.g)]. ¿Qué significa «en todo momento»? ¿Cabe esa posibilidad cuando la iniciativa ya ha sido presentada (acompañada de las firmas necesarias) o ha dado lugar a una propuesta legislativa por parte de la Comisión? 
Como era de prever, el dilema en torno a si la decisión sobre el registro y la admisibilidad de una determinada iniciativa ha de adoptarse en el mismo momento o en momentos sucesivos centró la atención de los órganos que se fueron pronunciando sucesivamente sobre la propuesta de la Comisión ${ }^{39}$.

En el texto aprobado finalmente por el Pleno en diciembre de 2010, el PE se reafirmó en la idea de que sólo podrán registrarse las iniciativas que cumplan las condiciones previstas en el Reglamento, para evitar así que se

39 En su nota del 7 de junio, la Presidencia del Consejo se inclina también por un control en dos etapas, pero refuerza la capacidad de la Comisión para denegar el registro no sólo de las propuestas abusivas, poco serias o que de modo manifiesto vayan en contra de los valores de la Unión, sino también de aquellas que «estén manifiestamente fuera del ámbito de aplicación de los Tratados». El CESE considera, por su parte, que los criterios expuestos en la propuesta de Reglamento como motivos para rechazar el registro de una propuesta dejan demasiado margen de interpretación. Por esta razón, propone que lo único que se examine en la fase de registro sea si la iniciativa tiene «unidad de contenido» (y no agrupe diversas cuestiones en una única propuesta); si contiene afirmaciones difamatorias para individuos o grupos; y si infringe la Carta de los Derechos Fundamentales y los valores de la Unión. El Comité de las Regiones aboga, en cambio, porque el control de la admisibilidad de las iniciativas se efectúe ya en el momento del registro, para evitar así que los organizadores inviertan tiempo y dinero en una propuesta que finalmente no será admitida. La decisión sobre la admisibilidad de una iniciativa, que la Comisión adoptará en un plazo de dos meses a contar desde la recepción de la solicitud, no podrá fundarse en consideraciones de oportunidad política. La propuesta se considerará admisible si satisface las siguientes condiciones: que se refiera a una cuestión sobre la que puede adoptarse un acto legislativo de la Unión a los efectos de aplicación de los Tratados; que la Comisión esté facultada, en el ámbito de sus competencias, a presentar una propuesta; que respete los valores y principios fundamentales de la UE, así como los derechos y libertades consagrados en la Carta de los Derechos Fundamentales de la Unión; y que sea conforme con el principio de subsidiariedad (en los ámbitos que no sean de la competencia exclusiva de la UE). La decisión, que se notificará al organizador de la iniciativa y se publicará en el Diario Oficial de la UE, podrá recurrirse ante el Tribunal de Justicia (arts. 263 y 265 del TFUE).

No muy distinta es la posición mantenida por los ponentes del documento que sirvió para abrir la discusión en la Comisión Constitucional del PE. Sugieren que la verificación de la admisibilidad se realice en el momento mismo del registro o bien tras la recogida de 5.000 firmas, una cifra asequible que acredita un cierto apoyo popular, sin que represente un coste excesivo para los promotores, y evita, al mismo tiempo, una sobrecarga de trabajo a la Comisión. La novedad no está en los criterios que han de aplicarse, según los autores del documento, en este trámite de admisión, sino en el órgano que debe adoptar la decisión. Para proteger a la Comisión de la acusación de que su decisión responde a razones políticas y no jurídicas, se propone que no sea el único órgano que tome esa decisión, con la carga de trabajo que ello supone. Así se evitaría además que la Comisión fuese juez y parte. Es preferible la opción alternativa de designar un «comité de sabios» ad hoc, formado por expertos, académicos y juristas, para garantizar una mayor imparcialidad. Si el comité considera que la ICE es inadmisible, los organizadores podrían recurrir ante la Comisión, que podrá confirmar o anular la decisión del comité. Y si la Comisión la confirma, los organizadores podrán recurrir esa decisión ante el Tribunal de Justicia. 
recojan firmas de apoyo a una propuesta que resulte a la postre inadmisible. Y esa es justamente la idea que inspira la redacción final del artículo 4 del Reglamento. En el plazo de dos meses a partir de la recepción de la correspondiente documentación, la Comisión registrará sin demora la iniciativa propuesta con un número de registro único y remitirá una confirmación al organizador siempre que se cumplan las condiciones siguientes: a) se ha constituido un comité ciudadano; b) la iniciativa propuesta no está manifiestamente fuera del ámbito de competencias de la Comisión para presentar una propuesta relativa a un acto jurídico a efectos de aplicación de los Tratados ${ }^{40}$; la iniciativa propuesta no es manifiestamente abusiva, frívola o temeraria ni manifiestamente contraria a los valores de la Unión establecidos en el artículo 2 del TUE ${ }^{41}$. Si la iniciativa incumple alguna de estas condiciones, la Comisión rechazará su registro y en ese caso informará a los organizadores de las razones de dicho rechazo y de todos los posibles recursos judiciales y extrajudiciales a su disposición (se podrá impugnar esa decisión ante el TJCE).

Una vez confirmado el registro y publicada la propuesta, los organizadores podrán solicitar declaraciones de apoyo a los ciudadanos y facilitar el texto de la misma en otras lenguas oficiales de la Unión para su inclusión en el registro, pero la traducción será responsabilidad de los organizadores (art. 4.1).

Otra novedad introducida por el PE es la contenida en el artículo 4.5: «los organizadores podrán retirar una iniciativa propuesta registrada en cualquier momento antes de la presentación de las declaraciones de apoyo con arreglo al artículo 8».

En el Libro Verde, la Comisión planteó como una cuestión sobre la que merecía la pena reflexionar, la posible presentación de iniciativas sucesivas sobre el mismo asunto. Es una hipótesis que, en principio, no puede descartarse. Aunque la transparencia del sistema de registro podría evitar muchas duplicidades y repeticiones, puede darse perfectamente esa circunstancia. Habría que estudiar, por tanto, la conveniencia de establecer determinados filtros para evitar, por ejemplo, que vuelva a presentarse una iniciativa fallida (antes, al menos, de que haya transcurrido cierto plazo: una especie de cuarentena). Pero siempre con cuidado, con la debida cautela, porque iniciativas aparentemente repetidas o coincidentes, que se re-

40 Así, una propuesta en relación la sede del Parlamento Europeo no entraría en el ámbito de las atribuciones de la Comisión. La sede de las instituciones la determinan de común acuerdo los Gobiernos de los Estados miembros.

${ }^{41}$ Con esa referencia a los valores de la Unión se intenta cerrar el paso a posibles iniciativas promovidas por grupos extremistas que no comparten los valores democráticos con los que se identifica la UE. 
fieren al mismo asunto y contienen elementos similares, podrían no ser idénticas.

La Comisión incluyó en el cuestionario que se sometió a consulta una pregunta sobre el particular ${ }^{42}$, pero la opinión mayoritaria entre quienes respondieron fue que no era necesario regular específicamente esa eventualidad, entre otras cosas, por el enorme esfuerzo que supone volver a tramitar otra iniciativa. Y lo cierto es que nada se dice al respecto ni en la Propuesta de la Comisión ni en el Reglamento, de modo que la presentación sucesiva de la misma propuesta o de una propuesta similar sobre un mismo objeto no es óbice para su registro. Del mismo modo, no hay ninguna disposición que impida que se promuevan de forma simultánea iniciativas diametralmente opuestas.

\section{Procedimientos y condiciones para la recogida y verificación de firmas (arts. 5, 6 y 8)}

Los promotores de una iniciativa debidamente registrada se encargarán lógicamente de reunir las firmas de apoyo necesarias entre los ciudadanos, que, como es natural, no podrán apoyar una determinada iniciativa más de una vez. La Propuesta de Reglamento no impuso ninguna limitación al modo o el lugar en el que pueden recogerse las declaraciones individuales de apoyo ${ }^{43}$, siguiendo en este punto las opiniones expresadas por la mayoría de los interesados que participaron en la consulta. Es más, a la vista de las respuestas obtenidas ${ }^{44}$, se prevé expresamente que las firmas pueden recogerse también on line, por vía electrónica ${ }^{45}$. Ahora bien, para garantizar que éstas sean tan auténticas como las manuscritas y puedan ser verificadas del mismo modo, se exige que los sistemas de recogida en línea, a través de páginas web, estén dotados de dispositivos de seguridad adecuados

42 ¿Es conveniente introducir normas para evitar la presentación sucesiva de iniciativas ciudadanas sobre la misma cuestión? En caso afirmativo, ¿considera que la introducción de determinados elementos disuasorios o plazos puede ser la mejor manera de lograrlo?

${ }^{43}$ No se exige, por ejemplo, que la recogida de firmas tenga lugar en centros oficialmente designados al efecto.

${ }^{44}$ La posibilidad de recoger firmas on line es valorada de forma positiva por la práctica totalidad de los participantes, en la medida en que facilita la recogida. Sólo unos pocos prefieren un sistema basado exclusivamente en firmas recogidas en papel, al entender que las firmas on line no son suficientemente seguras. El resto está convencido de que el progreso tecnológico permite la utilización de estos sistemas on line con plenas garantías.

45 En el Reglamento se contempla expresamente la posibilidad de cumplimentar las declaraciones de apoyo mediante una firma electrónica avanzada (art. 5.2), además de a través de una página web. 
y que los Estados miembros certifiquen el cumplimiento de esas normas de seguridad ${ }^{46}$, sin perjuicio de la responsabilidad que incumbe a los organizadores en materia de protección de datos de carácter personal. Corresponde a la Comisión determinar las especificaciones técnicas necesarias para estos sistemas ${ }^{47}$.

En cualquier caso, para que la recogida de firmas sea válida, han de utilizarse los formularios de declaración de apoyo que se ajusten al modelo que figura en el anexo III, que incluye una serie de datos personales como nombre, apellidos, fecha de nacimiento, nacionalidad o domicilio ${ }^{48}$. Y se

46 Tienen interés las observaciones que hace el Consejo sobre esta verificación, que corresponderá al Estado miembro en que se almacenen los datos recogidos a través de ese sistema. Para empezar, ésta debería realizarse antes de proceder a la recogida de firmas de apoyo (y no antes de presentar dichas firmas, como señalaba la Propuesta de la Comisión), de modo que el organizador solamente podrá empezar a recoger declaraciones de apoyo on line cuando haya obtenido el certificado correspondiente, que se publicará en el sitio utilizado para la recogida de firmas electrónicas. Una observación plausible que ha sido acogida en la redacción final del Reglamento: «Antes de proceder a la recogida de declaraciones de apoyo, los organizadores pedirán a la autoridad competente del Estado miembro de que se trate que acredite que el sistema de recogida a través de páginas web utilizado para ello» es conforme con esas disposiciones. Los organizadores solamente podrán empezar a recoger declaraciones de apoyo mediante el sistema de recogida a través de páginas web «cuando hayan obtenido el certificado mencionado» (art. 6.2). Por otra parte, el Consejo insta a la Comisión a promover el desarrollo de programas informáticos de código abierto que cuenten con las características técnicas y de seguridad necesarias. Este programa, según la Comisión de Asuntos Constitucionales del PE, tendría que ser accesible de forma general y ponerse a disposición de los organizadores de forma gratuita. Esta sugerencia también ha sido atendida: «A más tardar el 1 de enero de 2012, la Comisión establecerá y mantendrá programas informáticos de código abierto que incorporen las características técnicas y de seguridad necesarias para el cumplimiento de las disposiciones del presente Reglamento en relación con los sistemas de recogida a través de páginas web. Los programas informáticos se pondrán a disposición de manera gratuita» (art. 6.2).

${ }^{47}$ La Comisión aprobará esas especificaciones técnicas «a más tardar el 1 de enero de 2012» (art. 6.5). Un compromiso que ha cumplido con la publicación en el DOUE del pasado 18 de noviembre del Reglamento de ejecución n. ${ }^{\circ}$ 1179/2011 de la Comisión, de 17 de noviembre de 2011, por el que se establecen especificaciones técnicas para sistemas de recogida a través de páginas web, de conformidad con el Reglamento n. ${ }^{\circ}$ 211/2011 del Parlamento Europeo y del Consejo sobre la iniciativa ciudadana.

${ }^{48}$ La cuestión de los datos personales que pueden exigirse a la hora de cumplimentar la declaración de apoyo es controvertida. En opinión del CESE, en el formulario propuesto (anexo III) se exigen de modo innecesario diversos datos personales, lo que dificulta la recogida de firmas. El Comité se muestra contrario a exigir dichos números de identificación y se remite a este respecto al dictamen negativo sobre la Propuesta del Supervisor Europeo de Protección de Datos (fechado el 21 de abril de 2010). Dado que no todos los Estados miembros exigen o conocen estos datos, y que se requieren documentos muy diversos según los Estados miembros, la recogida de firmas ya no se regiría por las mismas reglas. Para el CESE, los datos exigidos para establecer la identidad de una persona - nombre, dirección, fecha de nacimiento y nacionalidad - son suficientes. El Consejo cree que hay que distinguir el caso 
debería permitir que los ciudadanos europeos que residan fuera de su país de origen puedan apoyar iniciativas ciudadanas, del mismo modo que pueden votar en las elecciones al Parlamento Europeo ${ }^{49}$.

El Reglamento no alude expresamente a la posibilidad de revocar la manifestación personal de apoyo, a diferencia de la Resolución del PE de 2009, que sí reconocía esa facultad de revocación, que podría ejercerse durante el plazo establecido para la recogida de firmas ${ }^{50}$.

En cuanto a las exigencias y garantías relativas a la verificación y autentificación de las firmas, la Comisión ya había adelantado en el Libro Verde, después de sopesar las ventajas e inconvenientes de las distintas opciones ${ }^{51}$, que, en ausencia de un organismo a escala de la UE que disponga

de aquellos Estados en los que la indicación de esos documentos o números identificativos es obligatoria (el DNI o el pasaporte en el caso de España) de aquellos otros (Dinamarca, Bélgica, Alemania, Irlanda, Holanda, Finlandia, Estonia, Reino Unido y Eslovaquia) que no requieren datos personales identificativos distintos de los que figuran en el formulario (nombre y apellidos, domicilio, fecha y lugar de nacimiento, nacionalidad y dirección de e-mail). En todo caso, añade el Consejo, para la verificación de las declaraciones de apoyo no se requerirá la autenticación de firmas. En la versión final aprobada por el PE y el Consejo, se incluye un considerando (el 13) del siguiente tenor: «Con el debido respeto del principio según el cual los datos personales deben ser adecuados, pertinentes y no excesivos en relación con la finalidad para la que se recojan, se requerirá la transmisión de datos personales, incluidos, en su caso, un número de identificación personal o un número de un documento de identificación personal por parte de los firmantes de una iniciativa ciudadana propuesta, en la medida en que ello sea necesario para permitir la verificación de las declaraciones de apoyo por parte de los Estados miembros, de conformidad con la legislación y las prácticas nacionales». Los Estados disponen pues de un cierto margen de libertad a la hora de determinar los datos que se consideran necesarios, aunque en la mayoría de ellos se exigirá el número del documento nacional de identidad. La lista de los documentos aceptados por cada uno de los Estados figura en la parte $\mathrm{C}$ del anexo III.

49 Por lo que concierne a los nacionales de un Estado miembro residentes en otro Estado de la UE, tendrán la posibilidad de rellenar el formulario en el país de residencia, proporcionando los datos requeridos en ese Estado, de modo que su declaración de apoyo será verificada y contabilizada en dicho Estado, o bien hacerlo lo propio en el Estado del que es nacional. El que los ciudadanos de la Unión residentes fuera de la UE puedan firmar una iniciativa dependerá del Estado miembro del que sean nacionales. Más exactamente, de la capacidad de cada Estado para verificar las declaraciones de apoyo de sus nacionales residentes fuera de la UE. Las firmas de aquellos que sí puedan hacerlo se contabilizarán en el Estado miembro de su nacionalidad. Como ya indicamos, este derecho de participación no se extiende a los residentes que sean nacionales de Estados que no forman parte de la Unión.

${ }^{50} \mathrm{De}$ acuerdo con la fórmula sugerida por el PE, todas las personas que manifestasen su apoyo a una iniciativa recibirían de los organizadores una copia de su manifestación y otra de la declaración por la que certifican que han sido debidamente informados por los organizadores de la opción de revocar dicha manifestación. Demasiado complicado tal vez.

${ }^{51}$ Una primera opción sería encomendar esa tarea de verificar la autenticidad de las firmas a los Estados miembros otorgándoles para ello plena libertad. El único inconveniente de esta solución es que una misma iniciativa podría estar sujeta a normas de control muy diferentes en los distintos Estados, hasta el punto de que el proceso de recogida simultánea de firmas 
de las competencias o la información necesarias para comprobar la validez de la firmas, serán las autoridades nacionales las responsables de verificar y certificar los resultados de la recogida de firmas en su territorio. Tanto la Propuesta de la Comisión, primero, como el Reglamento, después, siguen esa misma pauta: con el propósito de reducir en la medida de lo posible la carga administrativa que han de soportar los Estados miembros, deja que ellos mismos decidan sobre el modo más apropiado de verificar o validar las firmas recogidas en apoyo de una iniciativa, de conformidad con las legislaciones y prácticas nacionales ${ }^{52}$. Se concede, pues, a los Estados miembros un amplio margen de flexibilidad a la hora de regular esta cuestión. Lo más probable es que recurran a las reglas que ya vienen aplicando en el caso de las iniciativas ciudadanas nacionales, que varían considerablemente de un Estado a otro ${ }^{53}$. Ese proceso de verificación les permitirá certificar en el plazo máximo de tres meses desde la recepción de la solicitud el número de firmas válidas recogidas en el Estado miembro en cuestión ${ }^{54}$. Esos controles podrán realizarse sobre la base de sondeos o muestreos aleatorios,

sería mucho más fácil en unos que en otros, con el consiguiente agravio para los ciudadanos de éstos últimos. En el extremo opuesto, podría imponerse como solución la plena armonización de los requisitos a escala de la UE. Estos requisitos se fijarían en el Reglamento y no se admitirían excepciones o especificidades nacionales. Esta fórmula tendría la ventaja de garantizar la absoluta igualdad de condiciones en toda la UE, pero impondría cargas adicionales considerables, tanto administrativas como reglamentarias, a los Estados miembros que ya cuentan con procedimientos al efecto. Una tercera alternativa consistiría en establecer ciertos requisitos básicos a escala de la UE para que, dentro de ese marco común, los Estados miembros pudieran adoptar medidas adicionales, siempre que no sean indebidamente restrictivas. Con independencia del enfoque elegido, hay una serie de cuestiones que deben resolverse: por ejemplo, si la firma de un ciudadano debe verificarse en el Estado miembro del que dicho ciudadano sea nacional o en el Estado en el que resida.

52 Para su debida verificación y certificación, los organizadores harán entrega de las firmas recogidas a las autoridades competentes utilizando el formulario que figura en el anexo V. De acuerdo con lo dispuesto en el art. 8.1, separarán las declaraciones de apoyo recogidas en papel, las que se hayan firmado electrónicamente utilizando la firma electrónica avanzada y las recogidas mediante el sistema de recogida a través de páginas web. Y remitirán las firmas al Estado miembro de que se trate, que será el de residencia o el de nacionalidad del firmante o bien el que haya expedido el documento de identificación personal facilitado en la declaración de apoyo.

53 En algunos Estados se establecen requisitos bastante estrictos en el momento de la recogida de firmas, exigiendo, por ejemplo, que los ciudadanos firmen las iniciativas en centros designados oficialmente al efecto o que esté presente un funcionario público o un notario para autenticar las firmas. En otros, en cambio, no se imponen requisitos específicos para la recogida de firmas, pero se prevé la verificación posterior de esas firmas por las autoridades, para comprobar tanto la validez de las firmas como el número de firmas recogidas.

${ }^{54}$ Las autoridades entregarán a los promotores de forma gratuita un certificado conforme al modelo que figura en el anexo VI, indicando el número de declaraciones de apoyo válidas recogidas en ese Estado miembro. 
que es el sistema de verificación más utilizado por los Estados miembros en relación con las iniciativas ciudadanas nacionales.

\section{Plazo de recogida de firmas (art. 5.5)}

Las firmas han de reunirse en un plazo determinado, aunque el Tratado no lo haya previsto. En los países en los que existen iniciativas ciudadanas, ese plazo oscila entre los 30 días de Letonia y los 18 meses de Suiza, pasando por los 9 meses prorrogables de España. El Reglamento, que sigue en este punto el criterio mantenido en su momento por la Comisión y el PE, prevé un plazo no superior a 12 meses, a contar desde la fecha del registro (art. 5.5), un período de tiempo que se estima suficiente dada la complejidad ligada a la dimensión europea, esto es, la dificultad objetiva que representa la necesidad de recabar apoyos en diversos Estados miembros. Al finalizar dicho plazo, se añade ahora en la versión definitiva del Reglamento, se indicará en el registro que el plazo ha expirado y, si procede, que no se ha recogido el número requerido de declaraciones de apoyo.

\section{La decisión sobre la admisibilidad de las iniciativas presentadas}

Este era seguramente el aspecto más polémico del proyecto de Reglamento. La Comisión, resulta obligado recordarlo ahora, se había mostrado en contra de un control de admisibilidad en el momento del registro y había dado a entender en su Libro Verde que podría prescindirse de dicho examen. Luego reconsideró, al menos en parte, su postura inicial y en su propuesta obligaba a los promotores de una iniciativa a solicitar de la Comisión una decisión sobre su admisibilidad tras haber recogido 300.000 firmas de apoyo provenientes de al menos tres Estados miembros (casi un tercio del millón que se exige como mínimo ${ }^{55}$. Se consideraba que esta cifra constituía una muestra suficientemente representativa para activar el control de admisibilidad. La Comisión dispondría entonces de dos meses (desde la recepción de la solicitud de los promotores) para evaluar si la iniciativa entraba dentro del campo de sus atribuciones y se refería a un asunto sobre el que la Unión podía adoptar un acto jurídico en aplicación de los Tratados y para tomar una decisión al respecto, que sería notificada a los promotores y se haría pública. Esta resolución no prejuzgaba en absoluto el signo de la

55 La cifra de 300.000 firmas resulta excesiva tanto para el Consejo, que propuso que se rebajase a 100.000, como para el CES, que estima que el examen de la admisibilidad debería llevarse a cabo una vez reunidas 50.000 declaraciones de apoyo de tres Estados miembros. 
decisión que la Comisión adoptaría más adelante sobre el fondo de la iniciativa.

Esta solución respondía a la convicción expresada por buena parte de los participantes en la fase de consulta de que la admisibilidad jurídica de una iniciativa debería examinarse antes de emprender (o de completar al menos) la recogida de firmas y antes, por supuesto, de que los Estados miembros procediesen a verificarlas. Se trataría de liberar a éstos de la carga de verificar las firmas recogidas en favor de una iniciativa que finalmente no será admitida. Con esta fórmula de compromiso, se establecía un control de admisibilidad, pero no al principio, en el momento en el que la iniciativa se registra, sino más adelante, una vez constatada su viabilidad.

Como ya señalamos antes, el PE mantuvo en su Resolución de diciembre de 2010 la tesis de que el control de admisibilidad de las iniciativas ha de realizarse en el momento del registro. Y esa es la postura que se ha impuesto finalmente.

\section{Examen de la iniciativa por la Comisión (arts. 9, 10 y 11)}

Una vez obtenidos los certificados a los que se refiere el art. 8.2, es decir, una vez que se haya recogido el número de firmas exigido y que éstas hayan sido validadas por las autoridades competentes de los Estados miembros mediante el correspondiente certificado, los promotores podrán presentar la iniciativa ante la Comisión ${ }^{56}$. De acuerdo con lo previsto en su Propuesta de Reglamento, la Comisión dispondría de un plazo de 4 meses para examinar las iniciativas presentadas conforme a las disposiciones del Reglamento. Es un plazo razonable desde la perspectiva de los ciudadanos pendientes de la decisión, aunque tal vez sea excesivamente breve para poder estudiar a fondo iniciativas cuyo contenido sea particularmente complejo ${ }^{57}$.

56 Cumplimentando el formulario que figura en el anexo VII, que irá acompañado de las copias de los certificados, aunque la Comisión puede reclamar los originales. Recibida la iniciativa, la Comisión la publicará inmediatamente en su sitio de internet.

57 De hecho, se venían barajando plazos algo más amplios. En su Resolución de 2009, el PE sugirió un plazo de 5 meses, que se desdoblaría en dos fases: la Comisión dispondría primero de dos meses para verificar la representatividad de la iniciativa, y seguidamente de tres meses para examinarla y tomar una decisión sobre el fondo de la misma. El Libro Verde propuso, por su parte, un período que no excediese los seis meses y en esos mismos términos se pronunció el Defensor del Pueblo. En las respuestas remitidas a la Comisión con motivo de la consulta pública, el plazo de 6 meses es la opción que más respaldo concita, aunque no faltan propuestas que fijan un plazo más corto o más amplio. Para algunas organizaciones, sería aconsejable que se contemplase la posibilidad de prórroga del plazo cuando el asunto entrañe una especial complejidad. 
Hay que tener presente, además, que en ese corto período de tiempo la Comisión, antes de analizar el contenido de la iniciativa, debe comprobar si ésta se ha presentado correctamente y cumple los requisitos de representatividad, esto es, si cuenta con las firmas de apoyo exigidas.

Pero los eurodiputados no tenían, al parecer, esa misma percepción, porque el PE redujo ese plazo a tres meses, que es el previsto finalmente en el art. 10.1.c) del Reglamento. Y eso no es todo. Dentro de ese plazo, la Comisión se compromete a recibir a todos los organizadores a un nivel adecuado para que puedan explicar en detalle las cuestiones que plantea la iniciativa [art. 10.1.b)] y les ofrece incluso la posibilidad de presentar la iniciativa en una audiencia pública que tendría lugar en el PE, con la participación de la Comisión y de otras instituciones u órganos de la Unión que deseen asistir (art. 11).

La Comisión expondrá sus conclusiones políticas y jurídicas sobre la iniciativa e indicará la acción que tiene previsto emprender (o las medidas que en su caso se proponga adoptar) para dar cumplimiento a la misma y las razones para actuar así o para no hacerlo, en una comunicación que será notificada a los promotores así como al PE y al Consejo, y que será publicada. Tiene que ser una decisión meditada y debidamente motivada, que puede consistir, por ejemplo, en el anuncio de la presentación de una propuesta legislativa ${ }^{58}$. Pero no está obligada a adquirir ese compromiso, porque la iniciativa carece de fuerza vinculante. Puede adoptar otras medidas en respuesta a la solicitud contenida en la iniciativa (elaborar un informe o estudiar más a fondo el tema, por ejemplo) o declinar sencillamente la invitación que le han formulado un millón de ciudadanos europeos, si considera improcedente o políticamente inconveniente la propuesta $^{59}$. La Comisión conserva íntegramente su derecho de iniciativa legislativa, pero sí tiene la obligación de considerar muy seriamente la iniciativa y explicar de una manera clara, comprensible y detallada las razones que le llevan a tomar una determinada decisión (tanto los motivos

58 El Reglamento no fija un plazo para la presentación de esa propuesta, una vez que la Comisión adopta la decisión. Pero no todos comparten ese criterio. En el documento de trabajo que se debatió en la Comisión de Asuntos Constitucionales del PE se decía que la propuesta debe elaborarse en un determinado plazo, que puede ser el mismo para todas las iniciativas o que puede fijarse individualmente para cada una de ellas.

${ }^{59}$ La decisión política de la Comisión no es susceptible de recurso. Cuestión distinta es que la Comisión se abstenga de todo pronunciamiento acerca de la petición contenida en la iniciativa. En ese supuesto, tanto el PE como el CDR proponen que el asunto se someta al examen del TJCE, de conformidad con las disposiciones pertinentes del Derecho de la UE. En todo caso, tanto el Consejo como el PE podrían hacer suya una ICE ejerciendo su derecho de iniciativa. Además, si cumple los requisitos reglamentarios, siempre podría transformarse una ICE rechazada en una petición al PE. 
que le llevan a emprender una acción como los que le llevan a no adoptar ninguna medida) ${ }^{60}$.

\section{Requisitos exigibles a los organizadores: transparencia y financiación (art. 9)}

La Resolución del PE de 2009 hacía expresa referencia al principio de transparencia, que impone a los organizadores de una iniciativa ciudadana debidamente registrada la obligación de «rendir cuentas públicamente de la financiación de la misma, incluida la procedencia de los recursos financieros». Más exactamente, lo que el Parlamento exigía en una de sus recomendaciones (la n. ${ }^{\circ}$ 9) era que los promotores presentasen, en un plazo razonable una vez concluido el procedimiento, un informe sobre la financiación de la iniciativa, que sería examinado por la Comisión y se publicaría junto con un dictamen.

Es evidente que para poner en marcha y llevar adelante una campaña en favor de una determinada iniciativa se requiere, en la mayoría de los casos, el apoyo y/o la financiación de una o varias organizaciones. Pues bien, en aras de la transparencia, la Comisión (en plena sintonía con la citada Resolución) sostuvo en el Libro Verde que se debe exigir a los promotores de estas iniciativas que proporcionen determinada información básica relativa a las entidades que apoyan la iniciativa y al modo en que tales iniciativas van a financiarse ${ }^{61}$. Esta información podría facilitarse en el trámite del registro y quedaría desde ese momento a disposición del público, sin perjuicio de que la necesaria actualización mientras se desarrolla la campaña. La legítima preocupación de la Comisión por la necesaria transparencia en el uso de este instrumento parece evaporarse en el proyecto de Reglamento, que apenas hacía referencia a esta cuestión ${ }^{62}$. Un silencio frente al que reaccio-

60 Vid. P.M. KACZYNSKY, The European Citizens' Initiative: A Proper Response from the Commission, Politics and Institutions, CEPS Commentaries, 8 january 2010, pp. 1-2.

${ }^{61}$ En las respuestas recibidas en el curso de la consulta, que incluía una pregunta al respecto, hay coincidencia en considerar que los promotores de una iniciativa han de proporcionar información sobre los apoyos y la financiación que han recibido para que los ciudadanos sepan exactamente quienes están detrás de la operación y quien corre con los gastos. Esta exigencia de transparencia suele verse como un modo de asegurar que las iniciativas sean realmente impulsadas y pilotadas por ciudadanos, y no tengan otro origen o naturaleza. Algunos creen, no obstante, que sólo las contribuciones económicas que excedan de una cierta cantidad deberían declararse para no sobrecargar de trabajo a los promotores

62 Se limitaba a decir, en el art. 4.1, que en el momento de registrar la iniciativa los promotores deben proporcionar la información contemplada en el anexo II, en particular sobre el objeto, objetivos, fuentes de financiación y apoyo a la propuesta. 
naron las instituciones que intervinieron con posterioridad en la tramitación de la Propuesta63.

En el Reglamento, que sigue, también en este punto, la estela marcada por el PE, sí se prevé que en el momento de presentar la iniciativa a la Comisión, los organizadores proporcionen también la información relativa a las ayudas y la financiación que se hayan recibido en relación con la iniciativa. Dicha información se publicará en el registro (art. 4.1) ${ }^{64}$.

Llama asimismo la atención el hecho de que no se haya previsto ninguna forma de financiación pública específica para este tipo de iniciativas, quizá para preservar la autonomía de quienes las impulsan ${ }^{65}$. En España, la LO 3/1984, de 26 de marzo, reguladora de la iniciativa legislativa popular prevé una compensación por los gastos derivados de la campaña de recogida de firmas, con una cantidad limitada a 300.000 e como máximo (aunque es un cifra revisable anualmente).

\section{Protección de datos de carácter personal (art. 12)}

La propuesta trata de garantizar que todos los actores respeten en todo momento y de forma rigurosa las normas relativas a la protección de datos

${ }^{63}$ Así, el Consejo propone que se exija a los organizadores en el momento de presentar la iniciativa que informen sobre todas las fuentes de financiación y los apoyos recibidos. El Comité de las Regiones sugiere que se incluya en el formulario que se recoge en el anexo VI la exigencia de que los organizadores adjunten el presupuesto de los gastos realizados y las fuentes de financiación utilizadas. Porque no tiene mucho sentido obligar al organizador a indicar las fuentes de financiación en el momento del registro, cuando es muy posible que no se conozcan todas las aportaciones económicas que se van a obtener. Es al final del proceso cuando debe exigirse un informe justificando los gastos efectivamente realizados y la procedencia de los recursos utilizados. El CESE, por su parte, insiste en que los organizadores, ya en la fase de recogida de firmas, deben proporcionar a los firmantes información sobre los medios de financiación y los apoyos a la iniciativa, en aras de la mayor transparencia posible.

${ }^{64}$ «Los organizadores deberán proporcionar, para el registro, y, si procede, en su página web, información actualizada periódicamente sobre las fuentes de apoyo y financiación de la iniciativa ciudadana propuesta». Para ello, utilizarán en el primer caso el formulario recogido en el anexo II, en el que se incluye un apartado 6 del siguiente tenor: «Todas las fuentes de apoyo y financiación a la iniciativa ciudadana propuesta en el momento del registro». Y en el momento de la presentación de una iniciativa ciudadana ante la Comisión (formulario del anexo VII) se pide también a los organizadores que indiquen «todas las fuentes de la financiación y del apoyo recibidos en relación con la iniciativa, incluidos los importes de ayuda financiera en el momento de la presentación» (apdo. 7).

65 Diversas organizaciones e instituciones defendieron en la fase de consulta la necesidad de un apoyo económico a los promotores por parte de la UE para mantener este instrumento en manos de los ciudadanos y evitar que la suerte de estas iniciativas dependa de la financiación privada. Y el CESE propone en su dictamen que cualquier iniciativa ciudadana que supere las 50000 firmas reciba una determinada ayuda financiera por parte de la Comisión. 
de carácter personal. Las exigencias de la Directiva 95/46/CE del PE y del Consejo de 24 de octubre de 1995 y del Reglamento (CE) n. ${ }^{\circ} 45 / 2001$ del PE y del Consejo de 18 de diciembre de 2000, son aplicables al tratamiento de datos de carácter personal que se realice en aplicación de este Reglamento. Además, para evitar cualquier ambigüedad, se designa a los organizadores de una iniciativa ciudadana como responsables del tratamiento y se fija el plazo máximo de conservación de los datos de carácter personal obtenidos con motivo de la presentación de una iniciativa ${ }^{66}$.

\section{Entrada en vigor, modificación de los anexos y cláusula de revisión (arts. 16, 22 y 23)}

De acuerdo con lo dispuesto en el art. 23, el Reglamento entrará en vigor a los veinte días de su publicación en el Diario Oficial de la Unión Europea ${ }^{67}$. Teniendo en cuenta que carecemos de experiencia en lo que concierne al uso de este instrumento de democracia participativa a escala europea, la Propuesta incluía una cláusula de revisión que obligaba a la Comisión a elaborar un informe sobre la puesta en práctica del Reglamento cinco años después de su entrada en vigor. Un plazo que, tras el paso del

${ }^{66}$ Siguiendo la recomendación formulada por el Consejo en su documento de junio de 2010, el PE incluyó en el art. 12.3 del Reglamento una cláusula en virtud de la cual los organizadores garantizarán que todos los datos personales recogidos en relación con una determinada iniciativa ciudadana no sean utilizados para otros fines que no sean los de verificar las declaraciones de apoyo recibidas y destruirán todas esas declaraciones y las copias de éstas en el plazo máximo de un mes desde la presentación de la iniciativa o de 18 meses después de la fecha de registro de la misma. El mismo compromiso se exige de las autoridades competentes en cada Estado miembro, que deberán destruir las declaraciones de apoyo recibidas un mes después de la expedición del correspondiente certificado (art. 12.4). Excepcionalmente, tales declaraciones y las copias correspondientes podrán conservarse más allá de los plazos previstos si fuera necesario para los procedimientos judiciales o administrativos en relación con una determinada iniciativa ciudadana (art. 12.5). En cuanto a la responsabilidad de los organizadores por los daños que pudieran causar con motivo de la organización de una iniciativa ciudadana (art. 13), los Estados miembros se comprometen a sancionar de forma adecuada las infracciones del Reglamento, en particular las declaraciones falsas de los organizadores y la utilización fraudulenta de datos. Esas sanciones serán «efectivas, proporcionadas y disuasorias» (art. 14).

${ }^{67}$ En la propuesta de la Presidencia del Consejo se introdujo una distinción entre entrada en vigor y aplicación: «el presente Reglamento se aplicará doce meses después de su entrada en vigor». Y parece que la distinción ha hecho fortuna, porque en la versión definitiva aprobada por el PE y el Consejo, se dice que el Reglamento se aplicará a partir del 1 de abril de 2012 (art. 23). En ese plazo de algo más de un año los Estados tendrán que adaptar sus respectivos ordenamientos nacionales a lo dispuesto en el Reglamento (en relación con las sanciones o las autoridades competentes para verificar las firmas, por ejemplo). 
proyecto por el PE, ha quedado reducido a tres años ${ }^{68}$. Además, considerando que puede resultar necesario introducir ciertos ajustes técnicos a los anexos a la luz de la experiencia adquirida, se habilita a la Comisión, por tiempo indefinido, para modificar dichos anexos mediante actos delegados, en la convicción de que tales ajustes no requieren una propuesta legislativa completa y está plenamente justificada en este caso la utilización de poderes delegados. En todo caso, esa delegación puede ser revocada en todo momento por el PE o el Consejo (art. 18.1).

\section{Una reflexión final sobre las expectativas que despierta la ICE}

En un artículo publicado en EL PAIS el 11 de enero de 2010 (¿Cómo se mide la voluntad de Europa?), Andreu Missé decía que «se trata de una de las disposiciones más innovadoras del Tratado de Lisboa, que supone un primer paso hacia la democracia directa». En esa misma línea, Sylvia Kaufmann, eurodiputada por Izquierda Unitaria Europea y ponente del informe del Parlamento sobre la ICE, aseguró que «es un primer paso hacia el desarrollo de una democracia directa supranacional». Me parece que exageran un poco. No estamos en rigor ante una institución de democracia directa: no se transfiere a los ciudadanos la capacidad de decisión en un determinado ámbito $^{69}$. Mediante estas iniciativas se insta, se invita a la Comisión a que presente un proyecto legislativo sobre un asunto concreto, pero no es una propuesta vinculante. La Comisión no está obligada a hacerlo.

No cabe duda de que la ICE apunta en la buena dirección, en la de reforzar la legitimidad democrática de la Unión. Podría reproducir aquí los lugares comunes en torno al déficit democrático de la UE, de la necesidad de pasar de la Europa de los Estados a una Europa de los ciudadanos, construida de abajo arriba. Pero no tiene sentido que me extienda sobre el particular. Me limitaré a decir que puede ser una herramienta útil para acortar distancias, para acortar la brecha entre ciudadanos e instituciones, para reactivar el compromiso cívico, la conciencia de pertenencia a una comu-

68 «A más tardar el 1 de abril de 2015 y, a continuación, cada tres años, la Comisión presentará al Parlamento Europeo y al Consejo un informe sobre la aplicación del presente Reglamento» (art. 22).

${ }^{69}$ La última palabra, la decisión final sobre el destino de estas iniciativas populares corresponde a nuestros representantes en el Parlamento. Pero en el contexto del actual debate en torno al déficit democrático de las instituciones europeas, la iniciativa legislativa de los ciudadanos puede contribuir a corregir las imperfecciones de la democracia indirecta ( LL'initiative législative des citoyens», en Rapport sur l'initiative legislative, aprobado por la Commission de Venise - Commission Europeenne pour la Democratie par le Droit - en su 77 sesión plenaria, Venecia, 12-13 de diciembre de 2008, n. ${ }^{\text {os }} 67$ y ss.). 
nidad política supranacional (que se percibe como una realidad remota) y contrarrestar la tendencia a la apatía política, en la medida en que los ciudadanos puedan promover de forma colectiva cambios legislativos y puedan sentirse protagonistas activos de la democracia. Y todo ello en un contexto de descrédito de la clase política, que no acierta a representar adecuadamente los intereses de quienes les eligieron.

A través de este cauce, ciudadanos y organizaciones de la sociedad civil podrán hacerse oír e influir directamente en la agenda política de la UE, en la definición de las prioridades, por primera vez en la historia. Porque quejarse no basta, no sirve de mucho. No se priva a la Comisión del monopolio sobre la iniciativa legislativa (la decisión final de presentar o no una determinada propuesta le seguirá correspondiendo en exclusiva), pero al atribuir a los ciudadanos las mismas facultades de promover esa iniciativa de las que ya disfrutan el Consejo de Ministros y el PE se subsana una evidente carencia ${ }^{70}$. Ya es hora de que se ofrezca a los ciudadanos la oportunidad de intervenir por sí mismos, sin la mediación de los partidos, en el proceso de construcción de la Europa del siglo XXI, en el futuro gobierno de Europa, más allá de su participación periódica en las elecciones. Estamos ante la primera herramienta transnacional de democracia participativa, una fórmula pionera en el mundo (es la primera vez que una organización supranacional adopta un instrumento de participación directa), que tal y como va a regularse no presenta contraindicaciones.

Mi valoración tiene que ser, por tanto, positiva, pero sobriamente positiva, sin echar las campanas al vuelo. No creo que pueda hablarse de un antes y un después de la entrada en escena de la ICE. O de un cambio radical en la forma de hacer política en la UE. Albergo serias dudas incluso sobre la virtualidad de esta nueva herramienta para revertir la tendencia al progresivo distanciamiento entre los ciudadanos y las instituciones europeas. No va a ser fácil involucrar a ciudadanos de diferentes países en un proyecto común.

70 Sobre el ejercicio de la potestad de iniciativa legislativa en el seno de la UE, vid. PONZANO, P., «Le droit d'initiative législative de la Commission européenne: théorie et pratique», Revue des Affaires européennes-Law \& European Affairs, Edit. Bruylant, Brussels, n. ${ }^{\circ}$ 1, 2009-2010; y SAURON, J.-L., Le puzzle des institutions européennes, GualinoLextenso éditions, $4 .^{\text {a }}$ ed., 2010, pp. 169-170. Este mismo autor analiza el posible impacto de la ICE en la dinámica institucional de la Unión en «L'initiative citoyenne européenne: une fausse bonne idée?», Questions d'Europe, n. ${ }^{\circ}$ 192, 31/01/2011, disponible en el sitio de la Fondation Robert Schuman. Vid., asimismo, VOGEL, M., Un modèle démocratique pour l'UE ? L'initiative citoyenne en question, Nouvelle Europe [en línea], 28/02/2011; y BOYER M. y FERRY, L., La démocratie participative à l'heure de l'initiative citoyenne européenne, Terra Nova, Note, 13/10/2010, pp. 1-7 (disponible en www.tnova.fr); EMMANOUILIDIS, J.A. y STRATULAT, C., Implementing Lisbon: A critical appraisal of the Citizens'Initiative. European Policy Centre, Policy Brief 2010. 
Por otra parte, a nadie se le oculta el riesgo de desnaturalización y apropiación de esta herramienta por grupos de presión o por minorías de signo populista, como ha ocurrido en California, por ejemplo, con los referenda. Creo que en el marco de la UE son los colectivos mejor organizados, los que cuenten ya con una mínima estructura supranacional, como los sindicatos, las organizaciones ecologistas u otras organizaciones sectoriales o profesionales con acreditada capacidad de movilización, los que pueden sacar más provecho de este nuevo instrumento (como demuestra la experiencia española de la iniciativa legislativa popular).

Muchos confían en que pueda contribuir a crear un genuino espacio público europeo a medio o largo plazo $^{71}$, a superar la limitada perspectiva de las opiniones públicas nacionales, a despertar interés por los avatares de la política europea, al alumbramiento, en suma, de una sociedad civil europea, más articulada, mejor organizada. Pero no conviene crear demasiadas expectativas sobre su alcance potencial. Todavía es pronto para saber cuál va a ser su rendimiento, su impacto real en la dinámica institucional europea, en el proceso de toma de decisiones. En todo caso, parece necesario diseñar y ejecutar una campaña de información para difundir entre los ciudadanos europeos las características de esta nueva herramienta que se pone a su disposición, para que tengan conciencia de su existencia, de las posibilidades que ofrece y de las condiciones a las que se somete el ejercicio del derecho cuya titularidad les ha sido reconocida por los $\operatorname{Tratados}^{72}$.

En el momento en que se escriben estas líneas (finales de noviembre de 2011), se ha iniciado la cuenta atrás para la presentación de las primeras iniciativas en abril de 2012 y parece que son bastantes los grupos en toda la geografía de la UE que están poniendo a punto la maquinaria para estrenar con éxito este nuevo cauce de participación, preparando las correspondientes campañas de difusión de sus propuestas y recogida de firmas. Cuestiones relacionadas con la protección del medio ambiente, la defensa de los

${ }^{71}$ La UE «se diferencia del constitucionalismo tradicional que exigía unidad de demos, lo que muchas veces suponía también unificación lingüística, cultural o religiosa. Esta disociación de lo identitario y lo político constituye una de sus innovaciones más interesantes, planteándose así la posibilidad de una democracia sin demos o con demoi diversos, con un pueblo poco definido, mal limitado, poroso, no contrapuesto necesariamente a otros» (INNERARITY, D., «El espacio público europeo», Fundación Manuel Giménez Abad, 2009, p. 6; publicado antes en Claves de razón práctica, n. ${ }^{\circ}$ 175, 2007, pp. 24-31). Vid., también, BALIBAR, E., We the People of Europe: Reflections on Transnational Citizenship, Princeton University Press, 2004; y L. BLONDIAUX, Le nouvel esprit de la démocratie. Actualité de la démocratie participative, Ed. Le Seuil, 2009.

${ }^{72}$ La Comisión debería elaborar una guía completa y de fácil consulta que permita familiarizarse con las distintas etapas del procedimiento y brinde la ayuda necesaria a los organizadores. 
derechos socio-laborales o de los consumidores y la renovación del marco institucional van a ser seguramente el objeto de muchas de estas primeras iniciativas ${ }^{73}$.

Por otra parte, los 27 Estados miembros tendrán que esforzarse en la puesta a punto de los instrumentos normativos, organizativos y logísticos para poder hacer frente en su momento a las responsabilidades contraídas a nivel nacional. Un esfuerzo que deberán desplegar también, en paralelo, las instituciones de la UE, para garantizar que todo estará listo cuando se registren las primeras propuestas ${ }^{74}$.

73 Circulan rumores de que pueden estar preparándose iniciativas para aprobar una norma sobre el derecho a la información a escala europea, para crear una tasa sobre transacciones financieras o sobre las emisiones de dióxido de carbono, o en relación con los productos modificados genéticamente (Greenpeace ya puso en marcha una campaña de recogida de firmas en 2010), por poner sólo algunos ejemplos.

${ }^{74}$ A la hora de poner en práctica las previsiones del Reglamento, los Estados han asumido, entre otras obligaciones, la de verificar y certificar los procedimientos de recogida de firmas. En algunos países, como Finlandia, Austria y Alemania, es necesaria una reforma legal para designar a las autoridades nacionales que se responsabilizarían específicamente de esa certificación, mientras que en otros, como Francia, Holanda o Portugal, no haría falta esa reforma. Por lo que concierne a las instituciones comunitarias, una vez aprobado el Reglamento n. ${ }^{\circ}$ 1179/2011 de la Comisión, por el que se establecen especificaciones técnicas para sistemas de recogida a través de páginas web, quedan pendientes otros flecos, como la organización de la audiencias públicas (public hearing) en la fase final de la tramitación de una ICE, un asunto en el que tendrán que ponerse de acuerdo la Comisión y el PE. Para tratar estas cuestiones, la Comisión ha organizado una Conferencia sobre la ICE que tendrá lugar el 26 de enero de 2012 en Bruselas, bajo la presidencia del Vicepresidente Maroš Šefčovič. 